ELOHI

Peuples indigènes et environnement

9 | 2016

Voyageurs et naturalistes

\title{
Viajeros y naturalistas (s. XV-XIX, Europa- América) o cómo viajar sin precauciones por un tema torrentoso
}

Antoine Ventura

\section{(2) OpenEdition}

Journals

Edición electrónica

URL: http://journals.openedition.org/elohi/981

DOI: 10.4000/elohi.981

ISSN: 2268-5243

Editor

Presses universitaires de Bordeaux

Edición impresa

Paginación: 9-72

ISSN: 2431-8175

Referencia electrónica

Antoine Ventura, «Viajeros y naturalistas (s. XV-XIX, Europa-América) o cómo viajar sin precauciones por un tema torrentoso », ELOHI [En línea], 9 | 2016, Publicado el 01 septiembre 2018, consultado el 19 abril 2019. URL : http://journals.openedition.org/elohi/981 ; DOI : 10.4000/elohi.981 


\section{Viajeros y naturalistas (s. XV-XIX, Europa-América) o cómo viajar sin precauciones por un tema torrentoso}

\section{ANTOINE VENTURA}

EA 3656 AMERIBER, Université Bordeaux Montaigne

Quién no supiera nada, de antemano, acerca de semejante tema, y sin embargo se propusiera averiguar a qué remite, empezaría por una reflexión muy general entre conceptual y léxica. ¿Se trataría de hablar de viajeros por un lado, y de naturalistas por el otro, o de viajeros que hubieran dejado observaciones sobre las realidades naturales? ¿O se trataría más específicamente, de evocar la subclase de viajeros que a la vez eran naturalistas o pretendían actuar y/o actuaron como tales?

Entonces, una primera pregunta sencilla a la que se podría contestar en términos más o menos generales, sería la de saber a quiénes habría que designar como viajeros. Luego, entre ellos, y en particular para une época más reciente, digamos a partir del siglo XVIII (Pimentel: 47), quiénes fueron los naturalistas, dónde estuvieron, en qué se interesaron y qué consecuencias pudieron tener sus actividades en el campo del conocimiento y también en el desarrollo de las sociedades americanas objetos de sus observaciones. Ese impacto puede haber consistido en ayudar (de forma directa o indirecta) a tomar conciencia de la existencia de un pasado, de un patrimonio, de una cultura que merece ser integrada al acervo nacional y al conocimiento general. Puede también haber contribuido en la aparición de proyectos y de instituciones dedicadas a descubrir y proteger dicho pasado y dicho patrimonio. Y más seguramente, sirvió para el prestigio y desarrollo de las naciones de donde venían los viajeros naturalistas (Kury 2001: 147 y ss.)

En realidad, se trata de un tema vastísimo, y el que no elija proponer un estudio de caso se arriesga a un trabajo de enumeración o de síntesis. Solo que con semejante tema la síntesis podría ocupar varios volúmenes, tan abundante 
ha sido la literatura de viajes y tan abundantes también los tratados y relatos de sabios y amateurs curiosos a partir de la época moderna (véanse Duviols 1985; Ette; Cristóvão 1999 y 2003; Esteve Barba). - Juan Pimentel señala, en un capítulo de su estudio dedicado al siglo XVIII, la importancia de las "colecciones de viajes como género en la Ilustración", y examina detenidamente las obras compilatorias representativas, una siendo la del famoso autor de Manon Lescaut, el abate Prévost. Este solo caso de un escritor que publicó la Histoire générale des voyages en 21 volúmenes, a lo largo de la segunda parte del siglo ilustrado (incluso póstumamente), deja imaginar la riqueza y amplitud (enciclopédica) del material acumulado y el interés suscitado tanto por parte de los escritores como del público lector (Pimentel: 213-249, en particular 230 y ss).

Con toda modestia, en las líneas siguientes, no se alcanza más que una especie de repaso, que no se pretende exhaustivo ni mucho menos, un panorama esquemático (y que, es de esperar, no sea demasiado esquemático o erróneo). Mi intención es dar una idea de esa inmensidad galáctica suscitada a lo largo de cuatro siglos, suscitada por el encuentro definitivo entre dos continentes que se desconocían mutuamente, en muy pocas páginas por una parte, desde una perspectiva a la vez receptiva a las ciencias naturales y a la historia, por otra parte, y ahondando de vez en cuando en el caso mexicano, en tercer lugar; avanzando por periodo y tratando de señalar las orientaciones dominantes y algunas de las figuras más destacadas. Lo que obliga a un sobrevuelo por encima de la historia colonial de América (empezando desde Cristóbal Colón) para decir que quienes escribieron expresaron un interés, más o menos afirmado, por las realidades naturales, que a veces se tradujo en dedicación descomunal respecto a la descripción de dichas realidades (Bernardino de Sahagún, José de Acosta); y que América fue un espacio importantísimo de investigación, en particular por parte de Francia y España, cuando las expediciones tomaron un sesgo más científico, en el siglo XVIII, en el contexto de desarrollo de la historia natural (con Linneo y Buffon, y hasta Humboldt y algunos más a principios del siglo XIX).

\section{Donde se dice que viajes y viajeros famosos muchos hubo a/en América, a principios de la Edad Moderna (siglos XV-XVII)}

Para hablar de "viajeros y naturalistas ", se me ocurrió, en un primer momento, tratar de recordar desde cuando los viajeros han dejado huellas escritas de sus desplazamientos. Y me pareció, inmediatamente, muy amplio el tema ${ }^{1}$. Sin

1. Roberto González Echevarría, en su Mito y Archivo (1990), señalaba la importancia de los relatos de viajes científicos en el siglo XIX, reflejos de una "exploración científica [que] trajo consigo el segundo descubrimiento europeo de América" e hizo que los 
remontar a la Antigüedad europea ${ }^{2}$, pensé en Marco Polo y algunos más que viajaron, contaron y quizá en parte imaginaron sus viajes hacia el Oriente ${ }^{3}$.

\section{Colón y muchos más}

Para la región americana, evidentemente, desde la cultura europea, la cosa empezó con Cristóbal Colón quien escribió un diario (de a bordo), cartas, etc. (Textos y documentos completos, edición de Consuelo Varela; Esteve Barba: 2135), siguió con otros muchos, entre los cuales Hernán Cortés y sus propias cartas (Cartas de relación, edición de Manuel Alcalá; Esteve Barba : 154-161) en las que fue explicando qué iba haciendo en las tierras mexicanas para imponer la autoridad de España ${ }^{4}$.

También son muy conocidos otros navegantes y soldados, y a veces sus relatos cuando escribieron ellos mismos. Los nombres más destacados corresponden a personajes del siglo XVI, sean españoles e italianos, sean sus adversarios ingleses.

Américo Vespucci (1454-1512) viajó a América, probablemente varias veces, sin que se sepa a ciencia cierta cuál fue su papel en dichas expediciones que en parte coincidieron con las de Colón, aunque se hicieron al servicio del rey de Portugal principalmente, también de Castilla y siempre de la familia de los Medici; sus cartas fueron descubiertas tardíamente, a no ser las publicadas en 1504 bajo el título de Mundus Novus, que tuvieron mucho éxito (Alorge e Ikor: 71 y siguientes). Antonio Pigafetta (1491?-1534) escribió acerca de los viajes de Fernando de Magallanes a cuya tripulación pertenecía, la primera edición fecha de 1524, en francés, Le voyage et navigation faict par les spagnoles és isles

\footnotetext{
"naturalistas viajeros fueron los nuevos cronistas" (36). El crítico cita algunos estudios o compendios al respecto, publicados en EE.UU.: Thomas L. Welch, Myriam Figueras, Travel Accounts and Descriptions of Latin American and Caribbean 1800-1920, New York: Organización de los Estados Americanos, 1982; Edward J. Goodman, The Exploerers of South America, New York: Macmillan, 1972.

2. Para ello, se puede leer, entre otras cosas, el ensayo de Juan Gil, "Viajes y viajeros. Modalidades y motivaciones desde la Antigüedad clásica hasta el Renacimiento" (véase bibliografía).

3. Para una muestra bastante exhaustiva de los diversos viajes y relatos de viajes a Asia, véase Michel Jan. Acerca de Marco Polo, Le Livre de Marco Polo (texte intégral mis en français moderne et commenté par A. t’Serstevens), París: Albin Michel, 1955, y Olivier Germain-Thomas, Marco Polo, París: Gallimard, col. Folio biographies, 2010. Acerca de antiguos viajeros peninsulares, véase Vicente Cantarino.

4. El mayaniste Arthur Demarest considera que la historia de la arqueología maya empieza con los primeros contactos europeos (Demarest : 45). Lo mismo se habrá de decir en cuanto a cualquier tipo de conocimiento relativo al llamado (en su tiempo) Nuevo Mundo, incluso antes si nos situamos en una perspectiva etnohistórica.
} 
de Mollucques; sólo se publicó en español en 1800 (Escritores de Indias II: 15; Esteve Barba : 50-54).

Después de este primer grupo de navegantes italianos, se tiene que mencionar a una serie de grandes figuras inglesas. Francis Drake (1540-1596), navegante y explorador inglés, corsario al servicio de la corona inglesa, fue activo en particular en la zona del Caribe; en parte hecho famoso por haber sido el primero en vencer, en 1577, en una batalla naval contra buques españoles (Duviols 1985: 227). Existió una primera serie de relatos publicados en francés por Francis Fletcher, Le Voyage de l'illustre seigneur et Chevalier François Drach Admiral d'Angleterre, alentour du monde (París, Jean Gesselin, 1613; Duviols 1985: 388). Es también famoso Thomas Cavendish (1555-1592), otro navegante y corsario inglés, cuyas aventuras fueron contadas por un miembro de su tripulación, Francis Pretty, en 1598 (Duviols 1985: 381). Walter Raleigh (1554-1618) es el autor de una Historia del mundo y de otras obras sobre sus viajes y exploraciones en el Nuevo Mundo. A lo que parece, tuvo el proyecto de colonizar la América del Norte y atracó, para ello, en la actual Virginia, en 1584, gracias a los mapas del matemático Thomas Harriot que se había ido con él; y también desembarcó en el actual Guyana en 1617 para tratar de descubrir yacimientos de oro, tierra que declaró perteneciente a la corona inglesa. Se publicó un libro póstumo al respecto, Sir Walter Raleigh, His Apologie for his Voyage to Guiana (Londres: Moseley, 1650; disponible en línea en la página de Early English Book Online, consulta del 30 de agosto de 2016). Se le atribuye la introducción del tabaco en Virginia y en Jersey, así como de la patata en Inglaterra. Escribió también una Descripción de la Guayana, impresa sólo en 1751 (Duviols 1985: 210-212; al respecto, Esteve Barba cita otros datos: 383). Fue condenado a muerte por el rey de Inglaterra por haber fracasado en sus exploraciones para descubrir El Dorado (Duviols 1985: 213; sobre Raleigh en general, véase también Esteve Barba: 379-383).

La nómina de españoles que viajaron a y por el continente americano en los primeros tiempos tendría que ser muy larga, tan larga como el compendio de Esteve Barba. Él organiza su presentación en capítulos según criterios cronológicos ("Descubrimiento"; entre los viajes de Colón y la primera vuelta al mundo), pero rápidamente resultan insuficientes y aparecen temas y criterios geográficos (primeros historiadores generales, cronistas oficiales, Nueva España, Guatemala y Yucatán, etc.). Y también, y es lo que acaba por dominar como forma de organización de los datos, una clasificación de los autores según si fueron "conquistadores", "humanistas", "religiosos", "indios y mestizos", "viajeros y descubridores", "navegantes", "poetas", "historiadores", "cronistas", historiadores o escritores "de interés indígena" (Esteve Barba: 743-753), lo que permite percatarse de la variedad y de la complejidad de nuestro asunto. 
Mencionemos por lo menos a los que la memoria colectiva tiene más en mente (al lado de Colón y Cortés) y que representen algunas variantes geográficas. Bernal Díaz del Castillo (1492-1585), quien fue un soldado que participó en la invasión y dominación del imperio mexica dirigidas por Hernán Cortés, es el autor de la Historia verdadera de la conquista de la Nueva España (escrita en 1568), publicada en 1632 (la primera integral y no interpolada en 179495, según Escritores de Indias II: 39; Esteve Barba: 161-169). Lope de Aguirre (1511?-1561) fue otro soldado español conocido por sus viajes terrestres de exploración y búsqueda de riquezas, en particular en la zona de la actual Venezuela, para encontrar la mítica ciudad de El Dorado (Esteve Barba evoca al personaje al hablar de la "segunda expedición" y a los diversos participantes que dejaron algún escrito al respecto: 407-414). Fray Gaspar de Carvajal (15041584) fue el autor de la Relación del nuevo descubrimiento del famoso río Grande de las Amazonas, que relata la expedición del capitán Francisco de Orellana en la que participó y que llevó a descubrir el río Amazonas (Duviols 1985: 43; Esteve Barba lo presenta como el cronista de la "primera expedición" en busca de El Dorado: 404-408). En Carvajal encontramos las conocidas descripciones de las amazonas, mujeres fabulosas que encabezaban las tropas de indios para luchar contra las españolas. Álvar Núñez Cabeza de Vaca (1507-1559), otro soldado, es el autor de los Naufragios (1542), bajo el título de Relación que dio Álvar Núñez Cabeza de Vaca de lo acaescido en las Indias en la armada donde iva por gobernador Panfil de Narváez (Naufragios, Cátedra: 64); cuenta una expedición marítima a la Florida durante la cual se murieron muchos españoles, y sus consecuencias, quedándose el autor y algunos más prisioneros de los indígenas del sur de los Estados Unidos actuales, durante varios años.

A lo largo de los siglos XVI y XVII se fueron publicando relatos de viajes a América ${ }^{5}$, también por parte de navegantes y tripulantes holandeses, alemanes, italianos y muchos otros franceses e ingleses (véase Duviols 1985: 333-426); como por ejemplo Jacques Cartier (1491-1557), navegante y explorador francés, autor de Voyages au Canada (1534-1541). Éste es conocido por su papel en el asentamiento de los primeros colonos franceses en América del Norte. El rey de Francia Francisco I le había encargado encontrar una ruta para llegar a Asia por el norte de América, para evitar las zonas controladas por España (Clément 2012: 22 y siguientes).

Merece la pena citar también a otro inglés, o irlandés más precisamente, Thomas Gage, (1600?-1656), misionero dominico autor de una Nueva relación que contiene los Viajes de Tomás Gage en la Nueva España durante el año 1625 y

5. Acerca de viajes exploratorios españoles hacia el Océano Pacífico en los siglos XVIXVII, véase Esteve Barba: 567-575. 
siguientes (versión original en inglés, Londres: R. Cotes, 1648). Anduvo viajando por Nueva España durante 12 años antes de volver a Europa y hacerse anglicano. Se consideran interesantes, desde un punto de vista etnohistórico, sus observaciones acerca de México y Guatemala (en el título completo original, muy largo, cita Xalapa, Tlaxcala, México, Oaxaca, Chiapas, Guatemala, y también Nicaragua, Costa Rica, Panamá, Portobelo, Cartagena y La Habana, entre otros lugares; Duviols 1985: 403-406).

Por las mismas razones, es decir por haber evocado con cierta precisión la Nueva España, para el caso, hay que citar a Giovanni Francesco Gemelli Careri (1651-1725), viajero sin obligaciones ni misiones precisas, que salió de Europa en 1693 para sólo volver en 1698 después de haber dado una vuelta completa al mundo. Publicó en 1699-1700 un libro al respecto, Giro del mundo (Nápoles: G. Roselli), que consta de 6 tomos, el último dedicado a la Nueva España (512 páginas en $8^{\circ}$ ), con relatos sobre el origen de los mexicas, un calendario, representaciones de Tlaloc y otros dioses, de Moctezuma y Cuautémoc, y de plantas tales como el cacao, la vainilla, el aguacate, el zapote, el mamey y algunas más. Se editó una versión española de este tomo en México en 1955 bajo el título de Viaje a la Nueva España - México a finales del siglo XVII (Duviols 1985: 426$429)^{6}$.

Es de recordar que el perfeccionamiento de las técnicas de imprenta conjugándose con las de navegación y la expansión de los conocimientos geográficos entre los siglos XV y XVI dio lugar a una gran actividad editorial y a la publicación de varias compilaciones de relatos de viajes como la del famoso holandés Richard Hakluyt, Principal Navigations, Voyages and Discoveries of the English Nation, a finales del siglo XVI, y muchas más a continuación (Cristóvão 1999, "Introdução. Para uma teoría da Literatura de Viagens": 26-27).

\section{Lógicas y categorías históricas}

Frédéric Mauro (véase bibliografía) articula una síntesis sobre los "grandes descubrimientos" entre tres etapas y varios grupos que serían: precursores; descubridores de las rutas marítimas; conquistadores y, luego un nuevo grupo de grandes exploradores cuya aparición sitúa hacia principios del siglo XVII (navegadores holandeses, ingleses, daneses que van a explorar los mares al este y al sureste de África, hasta Australia y Nueva Zelandia).

Entre los viajeros de principios de la época moderna, primero estuvieron los europeos que establecieron el contacto con el Nuevo Mundo, como se sabe, grandes navegantes y soldados, aventureros, misioneros y administradores

6. Une versión en francés de 1726 se puede descargar en el sitio de la Biblioteca Nacional de Francia : http://gallica.bnf.fr/ark:/12148/bpt6k15116001/f12.image (páginas consultadas el 2 de febrero de 2018). 
(Cristovão 1999, "A Literatura de Viagens y a Historia Natural": 185). A continuación, el acceso resultó restringido por España (González: 21, Duviols 1985: 247; Duviols 2012: 56) para proteger las tierras americanas bajo su control de la avidez de otras potencias marítimas europeas, franceses, holandeses e ingleses ${ }^{7}$. Por supuesto, las restricciones eran menos fuertes para los misioneros (Duviols 2012: 57). Estas condiciones de control de los Imperios (Clément 2012: 21) y la envidia de naciones como Francia, Inglaterra y Holanda implicaron la existencia de aquellas otras figuras, piratas, filibusteros, corsarios (que no escribían, en general y que, cuando lo hacían, contaban sobre todo los saqueos de las ciudades y puertos que atacaban; una gran parte de los relatos se refieren al Río de la Plata y a Chile; Duviols 1978: 16-19 y 90-146; Duviols 1985: 223-236) ${ }^{8}$. Como las demás potencias, España estableció el famoso monopolio del comercio con América mediante la Casa de Contratación (Lavallé: 124; Chaunu: 245-276 para un acercamiento problematizado). Quienes más viajaron por esas tierras tratando de sacar provecho de lo que fuera fueron ellos, esos Drake, Cavendish, Raleigh y muchos más; y algunos comerciantes también (Mongne: 12; Duviols 2012: 55 y siguientes; Depetris 2014: 131). En este sentido, Jean-Paul Duviols, hispanista que se especializó en la literatura de viajes sobre América, en uno de sus primeros estudios acerca de los viajes de franceses a América, distingue a los "descubridores y colonizadores" (1504-1617) de los "evangelizadores" (1612-1774) y de los "contrabandistas, espías, filibusteros y negreros" (15991760), así como distingue, a partir del siglo XVIII, los "viajes científicos" (16931830) de los viajes diplomáticos, comerciales y políticos (1766-1831; Duviols 1978: 2 y siguientes).

Con la llegada al Nuevo Mundo y su posterior ocupación, se dio una expansión extraordinaria de la realidad natural a la que muchos sabios europeos se mostraron muy sensibles, lo que se puede comprobar al echar un vistazo a la cantidad de estudios y compendios descriptivos publicados a lo largo de los siglos XVI y XVII ${ }^{9}$ y al pensar en la multiplicación de los gabinetes de curiosidades (Durand-Forest y Durand: 6; Clément 2012: 31; Allorge e Ikor: 73). "El descubrimiento, luego la exploración y la explotación extrema de las Indias occidentales y orientales multiplicaron los materiales de observación" (Halleux: 718, traducción personal). También se generalizaron los jardines botánicos

7. Acerca del interés de los ingleses por la región maya en el siglo XVI, véase Valencia. 8. Siendo una excepción del tardío siglo XIX, el pirata Miguel Molas del que trata Jorge Victoria Ojeda por interesar sus apuntes y demás mapas de la península yucateca.

9. Los mejoramientos técnicos de la imprenta ya aludido permiten multiplicar la difusión de los conocimientos (y de las creencias y fantasmagorías). Véase Michel Morange (53-56) evocando los libros de historia natural en el siglo XVI europeo; o también Juan Pimentel acerca de la literatura de viajes (29-47). 
durante el siglo XVI en las grandes ciudades de Italia, y luego de otros lugares de Europa (Durand-Forest y Durand: 6-7). El rey de Portugal incluso tuvo un parque zoológico a principios del siglo (Halleux: 717; Allorge e Ikor: 74-79, sobre el invento del herbario seco por Luca Ghini a mediados del siglo XVI). Y esto nos lleva a pasar a hablar de los naturalistas que también fueron viajeros, como Gemelli Careri, pero sobre todo sabios y eruditos que se interesaron en las realidades del Nuevo Mundo.

\section{¿Quiénes fueron los naturalistas en la época moderna?}

"Naturalistas" se dice de las personas que profesan las ciencias naturales o tienen en ellas especiales conocimientos, según el Diccionario de la Real Academia Española (edición de 1992) ${ }^{10}$. Y ¿desde cuándo se habla de ciencias naturales? Esta es una pregunta diferente de la que sería: ¿desde cuándo nos interesamos en la naturaleza y acumulamos conocimientos al respecto? Porque, evidentemente, se puede considerar que desde que los seres humanos aparecen y forman sociedades, van acumulando conocimientos sobre ellos mismos y los demás elementos del medio de vida. Huellas escritas del interés por la naturaleza las más antiguas que se hayan registrado son obras de Aristóteles (Halleux: 713 y ss.; Morange: 20 y ss.), ya muy preocupado por clasificar y describir los animales, por ejemplo (Partes de los animales; Duris y Gohau: 12). También son famosas las obras de Teofrasto (siglos IV-III a. de C.) acerca de las plantas (Historia de las plantas), de las piedras y de los seres vivos en general (De anima; Halleux: 714); Lucrecio (siglos II-I a. de C., De rerum natura) y Plinio el viejo y su Historia natural (siglo I a. de C.; ver Duris y Gohau: 13-14; Morange 25 y 35). Con el redescubrimiento de Aristóteles a partir del siglo XII se ven aparecer nuevas obras dedicadas al estudio o al compendio de conocimientos sobre la naturaleza, como la de Isidoro de Sevilla, y muchos más (Halleux: 714; Duris y Gohau: 13-14; breve síntesis sobre la botánica antigua y renacentista en Paso y Troncoso: 143-144).

Muchos desarrollos en botánica, zoología y biología, que se consideran como fundadores de estas disciplinas, van a darse a partir del siglo XVI que fue, sin embargo, un siglo en que todavía se publicaron grandes compilaciones de conocimientos sobra la naturaleza sin que sus autores hubieran practicado

10. En la edición de 1780 (véase el Mapa de diccionarios académicos en el sitio de la RAE), se decía, más precisamente: "El que trata, averigua y examina las virtudes, propiedades y calidades de los entes naturales, especialmente de los animales, plantas, minerales". A pesar de que ciertos términos como éste, "naturalista", aparezca tardíamente en la norma léxica (no existe en el diccionario de Sebastián de Covarrubias, 1611 y 1674), aquí se van a emplear sin excesivos miramientos. 
observaciones por sí mismos (Duris y Gohau: 15). Es también a partir de entonces cuando la astronomía y la meteorología se vuelven autónomas respecto a lo que iba a ser designado como ciencias naturales - estudio de los minerales, vegetales y animales (Halleux: 712). Lo que tuvo que ver con la botánica tenía que ver con la medicina y la curación, o con la agricultura y, hasta el siglo XVII, la fuente principal fueron los libros del griego Dioscórides (siglo I d. de C.; Halleux: 715). Fue durante el siglo XVII cuando la anatomía de los insectos (o artrópodos), en particular, conoció importantes progresos con los trabajos de varios sabios holandeses, en parte gracias al invento del microscopio (Duris y Gohau: 16-19).

\section{La curiosidad de los exploradores y los evangelizadores}

En los primeros tiempos del contacto entre Europa y América, el interés por las realidades naturales de las tierras transitadas se debió en gran parte a misioneros y médicos (Halleux: 718). Esto no quiere decir que los grandes viajeros antes mencionados no se hubieran referido al mundo natural. En efecto, se encuentran menciones de animales, plantas y minerales en los escritos de Cristóbal Colón y de Hernán Cortés (Gil 1989: 24 y ss.; Pardo Tomás y López Terrada: 38-47 y 61-65), por ejemplo, pero también de cronistas que nunca estuvieron en América como Pedro Mártir de Anglería y Francisco López de Gómara (Pardo Tomás y López Terrada: 52-57 y 117-125) ${ }^{11}$.

En cuanto a los misioneros y médicos, algunos de ellos intentaron desde un principio describir y comprender, a veces describir, comprender y condenar. Ya no se trataba sólo de contar lo des-conocido revelado por viajes y sus des-cubrimientos (o sea contactos con realidades des- o más bien no conocidas) sino también de profundizar en la comprensión de lo inmediato, de lo ya presente. No sólo declarar la existencia (efectiva o fantaseada) de realidades sino estudiar, o sea describir, clasificar, relacionar, interpretar realidades (Pardo Tomás: 19), ir más allá de la comprobación existencial, de la experiencia perceptiva, para llegar a alguna forma de comprensión y de sistematización, o sea de conocimiento de la naturaleza y de las culturas así como de las relaciones entre culturas y entorno. Ya Vespucci (El nuevo mundo, 1503?) hacía observaciones

11. Véase también Esteve Barba (55-64 acerca de Anglería y 105-113 acerca de López de Gómara). En sus Cartas sobre el Nuevo Mundo, Anglería refiere regularmente datos recabados acerca de América, incluso relata brevemente (pero varias veces) mitos caribes cosmogónicos con cierto desdén etnocéntrico (Anglería: 70 y ss.). En cuanto a la cuestión de la experiencia directa, también puede darse el caso de que se encuentren más datos (sobre un tema preciso) en obras de autores que no viajaron que en las de otros que sí lo hicieron (Del Pino Díaz 2006: § 18-25). 
de esta calaña, es decir acerca de los conocimientos por los pueblos originarios del interés terapéutico de las plantas de su entorno (Duviols 1985: 29).

Incluso Diego de Landa (1524-1572, fraile y obispo de Mérida), desgraciadamente tan famoso por su celo en la lucha contra la idolatría y las destrucciones afines que se le deben, como por sus aportes en el conocimiento de la cultura y de la escritura maya, en particular, se interesó en las realidades naturales de la península de Yucatán (Relación de las cosas de Yucatán, ¿1560?), como es sabido (véase, por ejemplo, Demarest: 46; Esteve Barba: 318-321). En una presentación anterior, ya me había referido a los capítulos finales de lo que nos llegó de su obra, señalando cómo el misionero expresa su admiración por la flora y la fauna de Yucatán y explica muy detenidamente las características geológicas e hidrográficas de la península (Landa: 117-137 citado en Ventura: 16). Del mismo modo, un misionero tan importante y tan preocupado por la conquista espiritual como Fray Toribio Motolinia (¿1482 o 1491?-1569; véase Esteve Barba: 192) dedicó, en la última parte de lo que ha sido recogido como la Historia de los indios de Nueva España (Relación de los ritos antiguos, idolatrías y sacrificios de los indios de la Nueva España, y de la maravillosa conversión que Dios en ellos ha obrado), media docena de capítulos a la descripción del relieve, de la fertilidad de las tierras sobre todo, e incluso a la de alguna que otra planta como el maguey (Tratado tercero, capítulo XIX, en Motolinia: 285-289).

Esteve Barba señala también el caso del jesuita Bernabé Cobo (¿1579?-1640), más naturalista que historiador, cuya precisión es notable en cuanto a descripciones de minerales y de plantas del Perú (pero su obra no fue conocida hasta el siglo XIX), tanto como su poca cordura en sus consideraciones sobre la historia de los pueblos originarios de los Andes (Esteve Barba: 556-560).

\section{La dedicación precursora de otros (Sur de América del Norte y Norte de América del Sur)}

En los imperios de las Indias occidentales de España y Portugal, muchos se especializaron en ello, como Gonzalo Fernández de Oviedo (1478-1557), funcionario que ocupó varios cargos entre los cuales cronista de Indias, autor de un Sumario de la natural historia de las Indias (Toledo: Ramón de Petras, 1526). Su obra más importante es la Historia general y natural de las Indias (Sevilla: Cromberger, 1535; en total fueron veinte libros). Se sabe, por ejemplo, que el Sumario, lo escribió a encargo del rey Fernando quien quería saber en qué consistían las realidades de su Imperio de Indias (véase Ballesteros Gaibrois y también Pardo Tomás: 43 y ss.). Es un catálogo acerca de los seres naturales (plantas y animales; los minerales en menor medida) presentes en los territorios cuya existencia acababan de descubrir los españoles. Fue también un gran viajero, que atravesó numerosas veces el océano Atlántico para informar y presentar 
quejas acerca de la administración de las Indias (Esteve Barba: 64-83, en particular 66-72). Esteve Barba lo considera como, primeramente, un naturalista, luego un historiador, y también (sorprendentemente) un etnólogo (72 y 82-83) - menos sorprendente si se toma en consideración la minuciosidad de sus descripciones de las costumbres alimenticias de los indígenas en la Historia general (Benat-Tachot: $\$ 55$ y ss.). Como naturalista, "se destacó como biólogo, por la cantidad, novedad y rareza de las especies que describió y por la exactitud y esmero de sus descripciones" (Esteve Barba: 79) ${ }^{12}$.

Por supuesto, está también el muy famoso fraile Bernardino de Sahagún (¿1499 o 1500?-1590, Historia general de las cosas de Nueva España, 1570). Siguen fascinando su ambición y los esfuerzos de conservación y registro desplegados que lo hacen ser considerado como uno de los mayores pioneros de la antropología cultural y el padre de la antropología del Nuevo Mundo (León-Portilla 1987: 7 y 9-10; Wachtel: 27 y 30; D’Olwer: 137-138). Llama la atención su manera de proceder: reunir y constituir grupos de informantes, unos ancianos y otros jóvenes aculturados que dominaban dos o tres idiomas, el náhuatl y además el español, a veces el latín (Sahagún 1829: III-IV; León-Portilla 1987: 90-94) y establecer un cuestionario previo para recoger datos sobre diversos aspectos de la cultura estudiada (Esteve Barba: 208-212, 211 en particular; D'Olwer: 135 y ss.). Varios estudios pormenorizados de la vida y la obra de Sahagún se han publicado, como el de D’Olwer (México, 1952). El trabajo de Sahagún, terminado a eso de 1569, nunca se publicó y circuló bajo diferentes formas manuscritas (fue objeto de censura a partir de 1577) hasta que empezó una labor de reconstitución de su obra durante el siglo XIX (D’Olwer: 98 y ss. y 175 y ss. ${ }^{13}$. Parecida admiración impone alguien como el padre José de Acosta (1539- ¿1599 o 1600?; Historia natural y moral de las Indias, 1590), considerado como uno de los grandes autores científicos del Renacimiento (Esteve Barba: 114-122, en particular 116), precursor en varios aspectos, sea por las realidades que le interesaron (el cielo, el clima, los vientos, la tierra, el relieve...), sea por sus hipótesis (tuvieron que venirse de otra parte los habitantes de las Indias; tiene que haber un pasaje o un lugar en el que se acercan los continentes),

12. Un estudio muy pormenorizado de la obra de Oviedo es el de Antonello Gerbi. Se publicó en italiano por primera vez en 1978. Gerbi también dedica unos capítulos a Colón (25-36), Vespucio (50-60), Pedro Mártir (66-95), Cortés (113-120) para decir que poco interés despertó en él el mundo natural, como tampoco lo despertó en Pigafetta (121-134); y a un puñado más de autores italianos y españoles menos conocidos.

13. Un compendio como el de la Flora medicinal indígena de México (1994) lo menciona en la dedicatoria (con tres otros históricos predecesores), lo cita en epígrafe y los autores del proyecto mencionan su trabajo como uno de los dos modelos seguidos en el compendio, el otro siendo el de las Relaciones geográficas (Zolla y Argueta: 12). 
y su independencia respecto a la cultura escolástica. Como el lector curioso puede observarlo con sólo recorrer el índice de su libro (Acosta 1894, tomo I: XVII-XXIII), a menudo va contrarrestando Acosta las enseñanzas de Aristóteles (así como las de Plinio y demás autoridades antiguas). Evidentemente, una parte de la obra está dedicada a denunciar la idolatría y sobre todo la influencia del Demonio (Acosta 1894, tomo II: Libro V); pero también comenta los sistemas de escritura en el Libro VI - un libro enteramente dedicado a la historia del Imperio azteca, desde sus orígenes hasta la muerte de Moctezuma II; es el último libro, el séptimo. Más relacionado con nuestros temas, el Libro IV está casi por mitad dedicado a celebrar las riquezas del subsuelo (oro, plata, azogue, esmeraldas, etc.), y en la casi otra mitad a describir la fecundidad de esas tierras en cuanto a flora comestible (raíces, hortalizas, frutas). Se termina con la evocación de árboles (ceibas, etc.) y animales (para la cría, esencialmente). Esteve Barba insiste, con muy buen criterio, en la cualidad de los raciocinios de Acosta y en la importancia que cobra, en su discurso, la razón. He aquí un ejemplo, cuando Acosta argumenta sobre la probabilidad de que llegaron al Nuevo Mundo sus primeros habitantes en condiciones geográficas y climáticas determinadas (y no gracias a la Providencia), sin restarle nada, con ello, al poder divino:

Porque pregunto yo, ¿con qué pensamientos, con qué industria, con qué fuerza pasó tan copioso mar el linaje de los Indios? Verdaderamente he dado, y tomado conmigo y con otros en este punto por muchas veces, y jamás acabo de hallar cosa que me satisfaga. Pero en fin diré lo que se me ofrece: y pues me faltan testigos á quien seguir, dejareme ir por el hilo de la razon, aunque sea delgado, hasta que del todo se me desaparezca de los ojos. Cosa cierta es, que vinieron los primeros Indios por una de tres maneras á la tierra del Perú? Porque ó vinieron por mar, ó por tierra: y si por mar, ó acaso, ó por determinación suya: digo acaso, echados con alguna gran fuerza de tempestad, como acaece en tiempos contrarios y forzosos: digo por determinación, que pretendiesen navegar é inquirir nuevas tierras. Fuera de estas tres maneras, no me ocurre otra posible, si hemos de hablar segun el curso de las cosas humanas, y no ponernos a fabricar ficciones poéticas y fabulosas: si no es que se le antoje á alguno buscar otra aguila, como la de Ganimedes, ó algun caballo con alas, como el de Perséo, para llevar los Indios por el aire: ó por ventura le agrada aprestar peces Sirenas y Nicolaos, para pasarlos por mar. (Acosta 1894, tomo I, Libro I, capítulo XVI: 73-74) $)^{14}$

En la formulación misma de sus objetivos de escritor, aparece la dimensión expresamente heurística de su trabajo, como por ejemplo cuando introduce el debate que propone acerca de la inteligencia de las poblaciones autóctonas

14. Este debate sigue en el capítulo XIX y XX del Libro I, y hasta el XXV con su propio punto de vista (el de los Incas, para el caso), pero lo cuenta Acosta con desprecio por tratarse de mitos (véase Acosta 1894, tomo I: 112 y 114). 
(Libro VI, capítulo I, "Que es falsa la opinión de los que tienen à los Indios por hombres faltos de entendimiento"), diciendo que escribe ese nuevo libro con el fin de "deshacer la falsa opinión, que comúnmente se tiene de ellos, como de gente bruta y bestial, y sin entendimiento" (Acosta 1894, tomo II: 141). En este capitulito que hace las veces de prólogo a la presentación de numerosos datos sobre la cultura y los conocimientos de los pueblos americanos, Acosta cita sus fuentes, pero ninguna parece ser directamente autóctona (ídem: 142).

Entre otros precursores de las ciencias naturales y humanas, otro fraile con un importante trabajo fue Cristóvão de Lisboa, considerado como el primer naturalista de la Amazonía con su inventario ilustrado, titulado História dos Animais e Árvores do Maranhão (una obra compuesta entre 1624 y 1627). Los métodos de trabajo (colectivo) de Cristovão de Lisboa (Amorim: 102) pueden hacer pensar en los que empleó el propio Bernardino de Sahagún. El trabajo del monje portugués hubiera sido superior al de Claude d'Abbeville (Histoire de la Mission des Pères Capucins en l'Isle de Maragnan et Terres Circonvoisins, 1614) por el uso de ilustraciones, la sistematicidad, y la calidad de las transcripciones de los nombres nativos de las especies (ídem: 103); y anterior al de los holandeses George Marcgraf y William Piso, autores de una Historia Naturalis Brasilae (1648).

Habría que citar también a Pedro Cieza de León (1521-1554), acerca de la región andina (Crónica del Perú, 1553), donde sirvió como soldado y como cronista entre 1535 y 1550 (Pardo Tomás y López Terrada: 126 y ss.). En su obra, describió sus viajes de Panamá a Potosí, y el relieve, el clima, la vegetación, la fauna de las zonas por donde pasó, así como detalló las culturas de las poblaciones locales. A pesar de su dimensión cronística, se la puede considerar también como una obra de geógrafo y naturalista (idem: 133-134).

Resulta imprescindible, por lo demás, citar a varios misioneros franceses y ginebrinos de la misma época, interesados en particular en las tierras de Brasil y que se esforzaron en describir sus especificidades naturales. Entre los más conocidos está André Thevet (¿1502 o 1504?-1592), autor de Singularitez de la France Antartique (París: Maurice de La Porte, 1558), una evocación de muchas regiones del Nuevo Mundo, el Brasil, el Río de la Plata, el Perú, la Nueva España, Cuba, etc., con descripciones de tipo etnográfico y naturalista a partir de entrevistas con los indígenas, aunque muchas de estas regiones no las visitó, a no ser el Brasil y el Río de la Plata. Fue también el autor de la Cosmographie universelle (París: P. L’Uilier, 1575), una obra mucho más fantasiosa, en la que se encuentran elementos que contribuyeron al mito de los gigantes de Patagonia, entre otras cosas (véase Duviols 1985: 28-29 y Duviols 1978: 38-41 y 49-51; así como Baudry de Vaux). Otro caso fue el de Claude d'Abbeville (¿15..?-1632) y su ya citada Histoire de la Mission des Pères Capucins en l'Isle de Maragnan (París: 
François Huby, 1614), acerca de intentos de asentamientos franceses en el Brasil, que también fue la razón de la presencia de Thevet en esa región (véase Clément 2012, y Duviols 1978: 71-75 y 10). Thevet, en particular, quien asumió el cargo de primer cosmógrafo del rey de Francia, fue el primero en informar sobre la existencia de una gran cantidad de animales del Amazonas y su floresta, como el manatí y el perezoso - se puede percibir la relación del escritor con sus fuentes de información indígenas en su forma de describir el perezoso (fragmento citado en Duviols 1978: 220); en efecto, Thevet se refiere a los conocimientos de los indígenas y cita también su léxico (para designar el animal y para designar el árbol de cuyas hojas se alimenta). Thevet también describió varias plantas y transcribió mitos de los tupinambás (Baudry de Vaux: 18 y 20). Tanto él como d'Abbeville informaron bastante sobre dichos indígenas, en particular. Esto no impide que su objetivo práctico fuera el de suscitar la migración de colonos franceses a esas tierras.

Habría que citar también a Charles Plumier (1646-1704) quien viajó tres veces a América, a petición de Luis XIV, el cual quería que le trajeran plantas medicinales de América (Deschamps y Marroussy: 39-45). Plumier estuvo en las Antillas y en México y escribió, como botanista del rey y excelente dibujante (Pinault Sorensen: 173-178), una Description des plantes de l'Amérique (París: Imprimerie royale, 1693; Duviols 1978: 147). Dio a varias flores de América nombres de funcionarios o, sobre todo, de botanistas amigos o conocidos de él: la begonia (homenaje a Michel Begon), la magnolia (a Pierre Magnol), la fucsia (a Leonard Fuchs), etc.

\section{Perspectiva etnohistórica}

Desde el punto de vista etnohistórico, evidentemente, hay que recordar que el interés por la naturaleza también constituía una dimensión cultural esencial entre los pueblos originarios. Sin embargo, si puede que hayan existido tratados de botánica y zoología entre los pueblos mesoamericanos antes del contacto con los europeos, no se conservaron (Durand-Forest y Durand: 9). En la antología de Miguel León-Portilla (Visión de los vencidos. Relaciones indígenas de la conquista, 1959) como las presentaciones de Esteve Barba (246-278), lo esencial de los documentos conservados que vienen evocados, fueran originales o copias (la mayor parte de la famosa colección de Laurenzo Boturini) ${ }^{15}$, remiten esencialmente al momento del contacto entre europeos y pueblos originarios, sobre todo a las luchas de resistencia contra los recién llegados (Códice Azca-

15. Las autoridades virreinales confiscaron la colección que resultó dispersada y/o perdida (Sánchez). Boturini dio a conocer posteriormente el contenido de su colección en un libro publicado en 1746, Idea de una nueva Historia General de la América septentrional (Madrid: Imprenta Zúñiga; véase Chavero). 
titlán, por ejemplo) ${ }^{16} \mathrm{o}$ a la colaboración con los invasores españoles (Lienzo de Tlaxcala, para citar el caso más conocido) ${ }^{17}$. En cambio, se sabe que Moctezuma II disponía de un Jardín botánico y zoológico y el análisis del léxico náhuatl hizo aparecer toda una serie de categorías descriptivas para las plantas (Durand-Forest y Durand: 10, citando estudios de Francisco del Paso y Troncoso, Manuel Maldonado Koerdell y Efrén del Pozo; alusión a ello en León-Portilla 1959: 181 y 185). En efecto, se han puntualizado muy claramente las disposiciones de los nahuas respecto a astronomía e historia natural. Por ejemplo, Paso y Troncoso, en un estudio publicado en 1886 acerca de la "La botánica entre los nahuas" (véanse las páginas: 140-144) ${ }^{18}$, para la evocación de la cual el estudioso mexicano echa mano de las fuentes coloniales tradicionales (sobre todo historiadores y cronistas) como Clavijero, Tovar, López de Gómara, Motolinia, Sahagún, Alva Ixtlilxochitl, Tezozomoc y demás. Paso y Troncoso insiste, en particular, en el hecho de que los conocimientos de historia natural estaban difundidos en todos los estratos de las sociedades mexicanas (no se trataba de una cultura de élites). El estudioso se muestra particularmente admirativo de la cualidad (precisión, coherencia) de la nomenclatura naturalista de los nahuas (ídem: 141-142 y también a partir de 172, su estudio de glosología botánica) y expone, en una presentación de veinte páginas, lo que pudo recabar como datos acerca de los Jardines botánicos en el Imperio mexicano ("Jardines botánicos de Anáhuac", ídem: 145-165), explicando que lo más probable es que esta cultura botánica se heredara de los toltecas. Paso y Troncoso presenta, en un primer tiempo, varios datos (encontrados esencialmente en la crónica de Alva Ixtlilxochitl) acerca de un jardín que habría sido el del señor de Tezcoco, Nezahualcoyotl, contemporáneo de Moctezuma II (Paso y Troncoso: 150-153); en un segundo tiempo, hace lo mismo acerca de los jardines de Tenochtitlán, en base a lo que contaron Cortés, Díaz del Castillo, Solís y algunos más (ídem: 156 y ss.). Todas las fuentes coinciden en evocar el interés del monarca mexicano por las plantas ornamentales y olorosas, así como por las medicinales. El estudioso termina afirmando que sin duda otros pueblos, mayas, tarascos, etc. se habrán dedicado a la observación de la naturaleza (ídem: 160 y ss). Ya no cabe duda, en efecto.

16. Visible, por ejemplo, en https://www.wdl.org/fr/item/15280/view/1/30/, consultas hechas en febrero de 2018.

17. Visible, por ejemplo, en http://www.latinamericanstudies.org/tlaxcala/Tlaxcala-lienzo.jpg, consultas hechas en febrero de 2018.

18. Véase todo el estudio en varias etapas en los Anales del Museo Nacional de México de ese mismo año, en línea: https://revistas.inah.gob.mx/index.php/anales/issue/ view/479/showToc, consultas hechas en marzo de 2018. 
Entre los autores anteriormente citados como precursores, alguien como Gonzalo Fernández de Oviedo, y los españoles de la primera mitad del siglo XVI, en general (Cieza de León hace excepción), no tomaron en cuenta ni trataron de captar los conocimientos de los pueblos originarios (Pardo Tomás y López Terrada: 195, 198 y 200), a diferencia de otros como Bernardino de Sahagún y Diego de Landa quienes, en ambos casos, fundamentaron sus descripciones y compilaciones de conocimientos en la consulta de informadores indígenas formados por ellos mismos. Por lo menos, como ya lo hemos señalado (Ventura: 16), en la edición a cargo de Miguel Acosta Saignes, el Quinto libro de la Historia general de las cosas de Nueva España está dedicado a "los augurios y pronósticos que estos naturales tomaban de algunas aves, animales y sabandijas para adivinar las cosas futuras" (Sahagún 1946, tomo I, 411 y ss.), el capítulo XXVIII del Décimo trata de las enfermedades y los remedios (ídem: tomo II, 255-275), el Onceno de las "propiedades de los animales, aves, peces, árboles, hierbas, flores, metales, y piedras, y de los colores" (ídem: tomo II, 317 y ss.). Por lo demás, en un conjunto como el de los Libros de Chilam Balam, se encuentran recetas médicas, mezcladas con muchas otras materias entre las cuales dominan las predicciones, las explicaciones calendáricas y las crónicas, que también remiten, en parte, al contacto (véase la "Introducción general" de Barrera Vázquez y Rendón: 9 y ss.; véase también Esteve Barba: 330-339 acerca de los escritos indígenas de la zona maya).

Las autoridades españolas, por su lado, demostraron su interés por conocer la medicina de los pueblos de América. Del mismo modo que la monarquía española hizo por conocer sus dominios recabando el máximo de datos posibles, como lo atestiguan las famosas Relaciones geográficas (para una presentación general de los documentos disponibles en cuanto a Nueva España, véase Carrera Stampa), se sabe que Felipe II también hizo por obtener datos al respecto por parte de sus representantes locales e incluso encomendó un trabajo sobre "terapéutica indiana" a su protomédico, Francisco Hernández (¿1515 o 1517?-1587; véase González: 36 y Del Pino Díaz 1987: 105 y ss.; Paso y Troncoso se refiere a menudo a su obra: 145-165). Había sido enviado por Felipe II a estudiar la flora de México y sus plantas medicinales. Fue el autor de Historia natural de Nueva España (manuscrito de 1576, véase Pardo Tomás: 158-176) - en "La botánica entre los nahuas", se alaba significativamente al médico español, pero también se insiste en el hecho de que sus fuentes fueron fundamentalmente lo que pudo saber de la boca de médicos indígenas (Paso y Troncoso: 167-168). Acerca de la compleja y desafortunada posteridad del trabajo de Hernández, se pueden consultar la síntesis de Somolinos y la de Durand-Forest (58 y ss.)

Se sabe también que un libro de plantas medicinales fue redactado a petición de Francisco de Mendoza, hijo del virrey de Nueva España, para ser entregado 
al príncipe Felipe, en 1552 (Libellus de medicinalibus indorum herbis, también conocido como Códice de la Cruz-Badiano, del nombre de los dos médicos indios que lo redactaron), una obra considerada como representativa de la "medicina mestiza" de Nueva España (Pardo Tomás: 123-125).

En ese sentido, no se puede pasar sin evocar a figuras del naturalismo español del siglo XVI, que no viajaron a América pero que sí se documentaron y escribieron obras importantes sobre la naturaleza americana. El médico Nicolás Monardes (¿1507 o 1508?-1588; autor de Historia Medicinal de las cosas que se traen de nuestras Indias Occidentales que sirven de Medicina, 1574), tuvo "un sinfín de informantes" (Pardo Tomás: 106), sea testigos solicitados por el propio médico (instalado en Sevilla) por su calidad de viajeros de vuelta de las Indias occidentales, sea por tener que tratarlos como enfermos, sea porque su fama lo llevó a que testigos espontáneos lo hicieran destinatario de muchas informaciones (ídem: 107). Pero, por detrás del éxito de sus publicaciones y de los datos proporcionados por sus informantes españoles y europeos en general, estaban conocimientos indígenas, por supuesto (ídem: 122 y ss.). Se sospecha, por ejemplo, que Monardes tuvo conocimiento del contenido del Libellus ofrecido al príncipe Felipe (ídem: 124).

Después del contacto y los numerosos escritos redactados al respecto (en cuanto a botánica, véase Durand-Forest y Durand: 7), parece ser que, durante el siglo XVII, la potencia ocupante y sus representantes se centraron sobre todo en la explotación del nuevo espacio, y decayó el interés en conocer el medio y los ocupantes originarios de ese espacio (Mongne: 12; Duviols 1978: 8-9). Mientras tanto se archivaron y se olvidaron las obras de Bernardino de Sahagún, de Diego de Landa y de muchos más. Sin embargo, en la perspectiva de la lucha en contra de la idolatría, se consignó "una considerable cantidad de información sobre la terapéutica, la brujería y las nociones corporales amerindias" (González: 19) - en obras de Ruiz de Alarcón (1629), Serna (1656), Núñez de la Vega (1702) - y en actas de procesos ocurridos en la región de Oaxaca y en la zona maya (para el caso de Nueva España).

\section{Viajeros y naturalistas a partir de finales de la época moderna}

Soldados y marineros iban a emprender grandes viajes bajo la autoridad de las monarquías y algunas de sus instituciones, con objetivos diversos, a la vez políticos y científicos (Martínez: 5 y 11, Kury 2001: 147-148). En efecto, en el siglo XVIII las exploraciones se vuelven sistemáticas y metódicas, con fines científicos (Mauro), por tierra y por mar. No dejaron de viajar los misioneros pero durante el siglo XVIII, se trató fundamentalmente de evangelización, asumida 
por los jesuitas en particular, de quienes se tiene una profusa correspondencia con las autoridades eclesiásticas europeas (véase Duviols 1985: 431-480) ${ }^{19}$.

Como se sabe, aquella curiosidad y determinación que aparece durante el siglo XVIII tuvo mucho que ver con la ideología pre-democrática y antropocéntrica de la Ilustración ${ }^{20}$, con los ideales promovidos por el Romanticismo, a continuación (Mongne: 12-13; Delgado López: 115), y también con intereses económicos y comerciales (Kury 2001: 162 y ss. acerca de Auguste de Saint-Hilaire [1772-1844] viajando por Brasil) relacionados con la revolución industrial y técnica que se iba dando en Europa, la cual implicó en el siglo siguiente una demanda creciente de materias primas que pudieran contentar la capacidad de transformación de las incipientes redes industriales de Inglaterra, Francia y demás potencias europeas, así como de Estados Unidos de América, unas décadas después (Manigat: 68-73). Pero este periodo, precisamente a partir de mediados del siglo XVIII, también fue el marco temporal del advenimiento de "las teorías sobre la inmadurez del continente americano" (Serna: 256; véase la evocación, en las páginas siguientes, de Buffon y de Pauw). En efecto, una de las preocupaciones de ese antropocentrismo ilustrado es la dominación, explícitamente la dominación/domesticación de la naturaleza, de los mares, de las distancias, de la prolífica diversidad de la realidad, mediante la sistematización de los conocimientos (enciclopedias, herbarios, floras...) y los viajes (véase también Pimentel: 152 y ss.; y Clément 1994 acerca del interés de Francia por la América española).

\section{Grandes y pequeñas figuras de exploradores, viajeros y sabios}

Como lo señala el hispanista alemán Ottmar Ette, los relatos de viajes de los siglos XVIII y XIX despertaron una fascinación impresionante que se ha mantenido "relativamente constante a lo largo de mucho tiempo" (Ette: 12), incluso hasta los últimos treinta años del siglo XX: "No cabe duda de que la fascinación despertada por los relatos de viajes, especialmente por las culturas lejanas, está marcada por la percepción de una alteridad cultural, social y política" (Ette: 13).

En el siglo XVIII, los nombres destacados pasan a ser nombres de navegantes y exploradores, sea británicos sea franceses, que exploraron en particular el Océano índico y sobre todo el Pacífico y que consiguieron dar la vuelta completa al mundo (circunnavegación) - después de la tripulación de Magallanes;

19. Pocos son los escritos que tuvieran que ver con la Nueva España, a no ser, por ejemplo, el libro de Joseph Neumann, publicado en Praga en 1730 a propósito de la evangelización de los Tarahumaras (Chihuahua), obra traducida en francés en 1969, bajo el título Révoltes des Indiens Tarahumars, 1626-1724 (Duviols 1985: 453).

20. "A partir del siglo XVIII desaparece el concepto místico-geográfico que el cristianismo había dado a la geografía terrestre" (Serna : 256). 
de Francis Drake, Thomas Cavendish y el holandés Olivier de Noort en el siglo XVI, entre otros ${ }^{21}$. Entre los más destacados, estuvo Charles Marie de La Condamine (1701-1774) naturalista y geógrafo francés, autor de Relation abrégée d'un voyage fait dans l'intérieur de l'Amérique méridionale. Depuis la côte de la mer du Sud, jusqu'aux côtes du Brésil et de la Guiane, en descendant la rivière des Amamzones, lue à l'assemblé publique de l'Académie des sciences (París: Pissot, 1745) ; y de Journal du voyage fait par ordre du Roi à l'Équateur (París: Imprimerie royale, 1751 ; Duviols 1985: 30 y 50 ; Duviols 1978 : 20-21 ; 150-153 y 154-156). Fue la primera expedición propiamente científica auspiciada por la Academia de Ciencias de París (Esteve Barba: 437 y 575 y ss.), dirigida por Louis Godin (1704-1760), para medir el arco del meridiano, en 1735 (Del Pino Díaz 1987: 106 y 107). Por "científica" hay que entender el hecho de definir un proyecto de manera moderna, o sea partir de una pregunta y determinar las observaciones necesarias para contestarla, llevarlas a cabo y resolver eventualmente la incógnita, que fue lo que propuso Godin, a propósito del debate sobre la forma exacta del orbe (si achatado en los polos o no), yendo a hacer mediciones en la región de Quito (ídem). Como lo dejan entender los dos títulos citados, después de acompañar la expedición a la región del Ecuador actual, La Condamine atravesó el norte de América del sur pasando de dicha región a la costa atlántica de Brasil, navegando para ello por el sistema fluvial del Amazonas (Esteve Barba: 437-440; Martínez: 12-13). La expedición tuvo que recibir el visto bueno de España quien hizo por figurar a través de dos jóvenes oficiales de la marina española, Jorge Juan (1713-1773) y Antonio de Ulloa (1716-1795). Por su lado también publicaron sus datos después de regresar a España (Relación histórica del viage a la América meridional..., y Observaciones astronómicas $y$ phísicas..., ambas obras de 1748; Esteve Barba: 576 y ss.; Martínez: 8-9) y unas Noticias americanas, más tardías (1772) pero de contenido relevante y variado. La importancia del viaje de La Condamine se percibe incluso al hojear los escritos de Humboldt ${ }^{22}$. Acompañó a La Condamine y Godin, entre otros, Joseph de Jussieu (1704-1779) ${ }^{23}$, uno de los tres hermanos naturalistas, con Bernard (1699-1777) y Antoine (1686-1758). Sólo o con algún otro miembro de la expedición, anduvo Jussieu por varios lugares de la región andina recogiendo ejemplares botánicos y animales ("Pelayo y Puig Samper: 70 y ss.), pero no

21. Véase la enumeración más precisa que propone Bougainville en el discurso preliminar a su Voyage autour du monde (2006, 7-20).

22. Aunque a veces también el alemán cite al francés para sospecharlo de captatio benevolentiae al evocar las Amazonas ante públicos europeos. Véase Jean Tulard (ed). L'Amérique espagnole en 1800 vue par un savant allemand, Humboldt, París, Calmann-Lévy, 1965,121 y ss.

23. Véase Chardon: 59-65 y Pelayo y Puig-Samper : 67-85. 
pudo acompañar a La Condamine en su travesía del subcontinente - siguió viviendo en América del Sur la mayor parte de su vida, trabajando como médico y como recolector e identificador de especies (quina, "canela" peruana, coca) que transmitía a su hermano Antoine (ídem: 74 y ss.), pero el material acumulado se perdió en los viajes y otra gran parte fue robada o se le perdió el rastro, por eso Joseph Dombey fue enviado para, entre otras cosas, recuperar dicho material (ídem: 84-85).

Otro personaje muy destacado fue el famoso James Cook (1728-1779), marinero y cartógrafo, explorador británico que se llevó a astrónomos y a un botánico a Tahití y Nueva Zelandia, Australia, Java y Sumatra. En otro viaje, llegó a la Antártida, y pasó por las islas Vanuatu, Marquesas y Pascua. Fue hecho miembro de la Royal Society. Hizo un tercer viaje durante el cual cartografió la costa occidental de Alaska. Escribió bastante sobre sus viajes ya que una edición en línea de 1821 reúne sus escritos completos en 7 tomos, bajo el título de The Three voyages of Captain James Cook Round the World ${ }^{24}$.

Otro francés famoso fue Louis-Antoine de Bougainville (1729-1811), marinero y explorador, autor de Voyage autour du monde (París: Saillant, 1771), en el que evoca su expedición científica a las islas de Polinesia. Anduvo viajando entre Río de Janeiro y el estrecho de Magallanes, principalmente, antes de irse a explorar los mares del sur (Duviols 1985: 474-475). Los viajes de Bougainville dieron lugar a la redacción de varios relatos escritos por sus acompañantes (Pernetty, Nassau, Chesnard, Duclos, Fesche, Vivez; véase Duviols 1978: 180-191). Citemos, para terminar este apartado (y se podría citar a muchos más), a JeanFrançois de Lapérouse (1741-1799), también marinero y explorador francés, émulo de Cook y de Bougainville. Se tienen escritos de su mano que han sido publicados de forma póstuma como la Relation abrégée du voyage de La Pérouse, pendant les années 1785, 1786, 1787 et 1788, publicado en 1799 en Leipzig ${ }^{25}$.

Para contrastar con estos muy famosos viajeros y centrar la atención en el mundo natural de una zona más limitada e identificada en aquella época, Nueva

24. Disponible en el sitio de la Biodiversity Heritage Library, página consultada el 30 de agosto de 2016. En el primer tomo, aparecen capítulos dedicados a los habitantes de Tierra del Fuego, a una anécdota ocurrida mientras recogía plantas, "An Account of what happened in ascending a Mountain to search Plants" (51-58) y a continuación se describen costumbres y comportamientos de la población de la isla de Otaheite o "King George the III's Island" así como las relaciones entre ellos y los expedicionarios, incluso un capítulo muy completo y detallado sobre la cultura del pueblo puesto en contacto con ellos, en cuanto al cómputo del tiempo y la manera de manejar números, sobre la lengua, el arte de la guerra, el gobierno, etc. (225-245).

25. Disponibilidad: Biblioteca de la Universidad de Estrasburgo, por lo menos. Y en ediciones de bolsillo, como la de La Découverte (París, 2005). 
España/México, dando así otro tipo de muestra de lo que también fueron viajes exploratorios, pueden ser mencionados varios viajeros/sabios franceses, como el astrónomo Jean Chappe D’Auteroche, autor de Voyage en Californie pour l'observation du passage de Vénus sur le disque du soleil, le 3 juin 1769, obra publicada en 1772 - es conocido por haber atravesado y descrito la región mexicana para llegar a la Alta California (Duviols 1978: 158-159); Pierre de Pagès, por su Voyage autour du monde, et vers les deux pôles, par terre et par mer (París: Moutard, 1782) que lo hizo viajar por Nueva España también (capítulos IV a VII), entre otros lugares, en busca del pasaje del Norte hacia el continente asiático (Duviols 1978: 161-162); Nicolas Thiéry de Menonville, botanista y autor de un Traité de la culture du nopal, et de léducation de la cochenille, dans les colonies françaises de l'Amérique; précédé d’un voyage à Guaxaca (París: Dekalain, 1787; Duviols 1978 : 163-164); y Charles Robin, naturalista, autor de un libro dedicado a contar un viaje a la Luisiana, la Florida y las Antillas, Voyage dans l'interieur de la Louisianne, de la Floride, et dans les isles de la Martinique et de Saint-Domingue en el que trata de geografía, historia natural, agricultura, comercio, industria y enfermedades (París: Buisson, 1807); dedica un capítulo (el 54 del tomo III) al riesgo de invasión de México por "los angloamericanos", señalando la riqueza de la región todavía novohispana, en cuanto a subsuelo y a fertilidad de los suelos (Duviols 1978: 164-166); por fin, un tal Monségur, capitán de la Marina real francesa, autor de un manuscrito titulado Nouveaux mémoires touchant le Mexique ou la Nouvelle Espagne, que concierne una estancia del oficial francés en los años 1707 y 1708 para informar a Felipe V sobre el estado del virreinato; constituye el manuscrito más completo que se pueda encontrar como testimonio sobre México a principios del siglo XVIII (Duviols 1978: 120-121 y Duviols 1985: 440-441) - pero el contenido de los capítulos tiene sobre todo que ver con cuestiones comerciales (realidades y perspectivas).

\section{Los famosísimos naturalistas (de bufete)}

Un gran cambio se fue dando entre finales del siglo XVII y principios del siglo XVIII en la concepción del conocimiento de la naturaleza (Martínez: 2-3). Se fue tratando, desde entonces, de describir y contar lo que se podía ver, sin tratar de descubrir relaciones ocultas entre los elementos, así nació la historia natural moderna con Buffon y Linneo (Spitz; Navarro: 412-416 para biografías sintéticas de los dos famosísimos), una etapa todavía algo alejada de lo que llegaría a ser la biología, en particular en la medida en que para un gran estudioso como el sueco Linneo (y la mayor parte de los sabios y científicos de la época moderna y contemporánea, excepto una parte de los ilustrados franceses), resultaba difícil pensar el mundo o la naturaleza sin referir su concepción a la voluntad divina (Duris y Gohau: 22-23). 
Y estos famosos, estos famosísimos naturalistas del siglo XVIII no eran viajeros, ni Buffon (Georges-Louis Leclerc de, 1707-1788, Historia natural de los animales, 1749; véase Pelt: 113 y ss.), ni mucho más Linneo (Carl von, 1701-1778), aunque sí hizo éste varios desplazamientos por Europa y expediciones en Laponia y demás regiones escandinavas (Deschamps y Maroussy: 53; Aguilar: 62). Ellos fueron los grandes divulgadores y clasificadores de las especies (Duris y Gohau: 20 y ss.). La clasificación de las plantas y de los animales, del naturalista sueco (Systema naturae, 1735) tuvo un gran impacto, así como el resumen de su clasificación, Philosophia Botanica (de 1751) que fascinó a Rousseau y a Goethe pero disgustó a Buffon (Deschamps y Maroussy: 54). La expresión "ciencia natural" la usa y la define Linneo como consistiendo en dos operaciones, describir y clasificar los cuerpos naturales por una parte, nombrarlos, por otra parte (Duris y Gohau: 23-24 y 22). En efecto, sus trabajos de mediados del siglo XVIII lo llevaron a usar una clasificación binomi[n]al por género y especie, propuesta en su Species plantarum (1753) que se ha vuelto el modelo de la taxonomía (Duris y Gohau: 26-27; Aguilar: 60-61).

Según Duviols (1978: 20), Buffon y Linneo tuvieron dos predecesores franceses que se dedicaron a observar la naturaleza americana, dos monjes, Charles Plumier (1646-1704) ya evocado y Louis Feuillée (1660-1724 o 1732). Éste también fue mandado por Luis XIV como sabio botanista, matemático y astrónomo, y viajó por los virreinatos del Río de la Plata y del Perú. Escribió un Journal des observations physiques, mathématiques et botaniques, faites par ordre du Roy sur les côtes orientales de l'Amérique méridionale et dans les Indes occidentales (París: Pierre Giffart, 1714-1715 ; Duviols 1978: 147-150).

Acerca de Buffon, por lo demás (en cuanto a los aportes respectivos del francés y del sueco, véase Galera), son bastante conocidas las críticas que se le hicieron a su concepción - así como a la de Cornelius de Pauw (1739-1799), autor de Recherches philosophiques sur les Americains ou Mémoires intéressants pour servir l'histoire de lespece humaine (1771) - de la naturaleza americana y de sus pobladores humanos, degenerados e inferiores a sus equivalentes europeos por varios motivos, entre los cuales, el clima. Se puede percibir a las claras la recepción de estas ideas en Nueva España, por ejemplo, al hojear la obra de Francisco Javier Clavijero (1731-1787), en su Historia antigua de México (1781), donde este último argumenta varias veces en contra de ese etnocentrismo, común para la época y, sin embargo, primario y normativo, del gran naturalista francés y del filósofo holandés ${ }^{26}$. Pero al rastrear dichas críticas (véase,

26. La edición de Mariano Cuevas para Porrúa (México) propone un índice alfabético donde resulta muy fácil ubicar los numerosos pasajes concernidos. Véase Martínez: 3-4, acerca de la mecánica política e ideológica dieciochesca en la que se insertan las consideraciones denigrativas sobre el continente americano de labbé Raynal, de Pauw 
por ejemplo, Clavijero: 680-681), lo que aparece sobre todo es la importancia determinante de la clasificación de Buffon para el sabio novohispano quien no se limitó a describir puros hechos históricos sino que trató el tema mexicano de modo enciclopédico, como se puede ver en el Libro I, en el VI y en el VII así como en diversas "disertaciones". La corrección de las concepciones de de Pauw y de Buffon vienen anunciadas por Clavijero en el prólogo a sus disertaciones (597-599). Cuando va contrastando metódicamente los tratados de historia natural de Buffon y de Hernández al principio de su cuarta disertación dedicada a los animales de México (671-694), se perciben también las deudas del sabio francés con su predecesor español, y mediante él, con los conocimientos de los indoamericanos. - Son también muy elocuentes las críticas dirigidas a Buffon por Thomas Jefferson en sus Notas sobre Virginia (1785), contradiciendo todos los rasgos que Buffon había formulado en el retrato del hombre americano, holgazán, débil, desprovisto de apetito sexual y de amor a sus parientes e hijos, cobarde, etc. (Roger: 59 y 61 y ss.).

A continuación se dieron más desarrollos en el campo de la química y de las ciencias naturales y mayores esfuerzos por clasificar. Aquí, habría que recordar aspectos de la historia de las ciencias europeas (Morange: 171 y ss.), y nombres como Georges Cuvier (1769-1832, Cuadro elemental de la historia natural de los animales, 1798; Lecciones de anatomía comparada, 1800), Jean-Baptiste Lamarck (1744-1829, Investigaciones sobre la organización de los cuerpos vivos, 1802, Filosofía zoológica, 1809; Nuevo diccionario de historia natural, 1817) y Charles Darwin (1809-1882, El origen de las especies, 1859) quienes aportaron mucho a la reflexión sobre el concepto de especie y su aplicación (en particular la idea de que la especie no puede ser una realidad permanente; véase Duris y Gohau: 36 y ss.; 57 y ss.) ; así como Antoine-Laurent de Lavoisier (1743-1794) y Louis Pasteur (1822-1895) en otros aspectos de los conocimientos de la naturaleza, física y química en el primer caso, química y médica en el segundo (Duris y Gohau: ; 179 y ss.; 81 y ss. $)^{27}$.

\section{Ciencia, política e instituciones}

Resulta claro, a través de los ejemplos abordados, que los viajes empezaban a dejar de ser viajes cuyo objetivo era directamente político y comercial para ser científico, en el sentido de que se trataba de recabar y establecer conocimientos,

y Buffon. Para un ejemplo de contraargumentos presentados a Cornelius de Pauw por su contemporáneo Antoine de Pernety, véase Martínez: 8-11.

27. En la fuente bibliográfica citada, los títulos de los estudios vienen en francés. La traducción es mía y sólo vale por su capacidad en dar a entender al lector el contenido de cada uno. Puede ser que algunas obras no se hayan traducido o lo hayan sido con ligeras diferencias de título. 
geográficos, astronómicos y demás (Duviols 1978: 19-20). Para lo cual, los jefes de las expediciones se llevaban a sabios en sus viajes marítimos (Allorge e Ikor: 471 y ss.). En el caso de Bougainville, la lectura de su "discurso preliminar" que abre el Voyage autour du monde revela a las claras el cambio de paradigma, en la medida en que el explorador francés empieza por lamentar el que la mayor parte de las circunnavegaciones se hayan dado para sacar provecho a expensas de los españoles y sin intenciones de aumentar los conocimientos "geográficos" ${ }^{28}$. Bougainville saluda también el primer viaje de Cook que acaba de concluirse e incluso cita el relato mandado por uno de los científicos de la tripulación a la Academia de Ciencias de París, "ayant enrichi le monde de grandes connaissances en géographie et de découvertes intéressantes dans les trois règnes de la nature"29.

En su primer viaje, James Cook, precisamente, se llevó a dos grandes naturalistas ingleses, Daniel Solander y James Banks (quienes fueron corresponsales de Linneo; véase Deschamps y Maroussy: 54). En este sentido, el tema del que vamos tratando también se podría entender como un cuestionamiento acerca de las relaciones entre viajeros o sea navegadores, marineros, por un lado, y naturalistas por el otro, cuando no se confundían las competencias de unos y otros (lo que implicaría el análisis de sus informes, cartas y demás escritos publicados, o no, desde esta perspectiva temática).

Duviols clasifica el viaje relatado por Bougainville en 1771 entre los viajes políticos y comerciales, pero reconoce que los objetivos eran a la vez políticos y científicos (Duviols 1978: 188-191): a nivel político, Bougainville estuvo encargado por el rey de Francia de entregar a España las islas Malvinas, a consecuencia de un acuerdo político entre los dos países (y de la toma de posesión de esas islas en 1763-64, por el propio Bougainville, en nombre de Luis XV). Del mismo modo, Duviols clasifica también el viaje de La Pérouse (nunca volvió de su viaje) entre los viajes políticos y comerciales (Duviols 1978: 195-196) y reconoce sin embargo que los objetivos del viaje de circunnavegación fueron a la vez comerciales y científicos.

28. Véase el "Discours préliminaire", en las páginas 7 y 8 de la versión original de la obra (París: Saillant y Nyon, 1771), en el sitio de la Bibliothèque Nationale de France, en línea : http://gallica.bnf.fr/ark:/12148/bpt6k852287d/f22.image, consultas de agosto de 2016. 29. El saludo a Cook no aparece en la edición de 1771 y tampoco en ciertas impresiones contemporáneas (la de Gallimard, col Folio, de 1982, por ejemplo), aunque todas pretendan referirse a la prínceps. Es que hubo una reimpresión en 1772, y ahí, Bougainville insertó dos páginas más en su discurso preliminar, como es de ver en la versión impresa por La Découverte en 2006, entre las páginas 16 y 18 (donde se encuentra la cita propuesta). Estas dos páginas proponen un resumen de la expedición de Cook, como los demás apartados de este discurso preliminar acerca de todos los navegadores que Bougainville reconoce como predecesores. 
Las instituciones que iban a definir la búsqueda de conocimientos (ya no, como con los heterogéneos gabinetes de curiosidades, tratar de reunir lo más extraño, sino reunir colecciones de todo lo que existe en la naturaleza), son los gabinetes de Historia natural, los jardines botánicos (que dejan de ser puros jardines de hierbas medicinales), los museos de Ciencias Naturales (Clément 2102: 31-32).

Los gabinetes de curiosidades fueron el objeto de una moda, a partir de mediados del siglo XVI, a continuación y paralelamente a esa moda del coleccionismo de antigüedades y medallas, que había aparecido con el Renacimiento (Duris y Gohau: 21-22; Pimentel : 147 y ss.). Se reúnen objetos etnográficos, cuadros, obras de platería y ejemplares de los tres reinos naturales (mineral, vegetal y animal). En el siglo XVIII, el éxito lo conocen los gabinetes de historia natural, aunque la diferencia entre estos y los gabinetes de curiosidades no queda muy clara (Duris y Gohau: ídem). Los grandes gabinetes, como el del rey de Francia, fueron la base de los museos de historia natural del siglo XIX (idem: 22).

Para precisar, recordemos que el Museo de Historia Natural de París fue creado en 1793 y fue la institución que abrigó como catedráticos a algunos de los estudiosos citados anteriormente como Cuvier y Lamarck. (Duris y Gohau: 41). La cátedra de Lamarck, la de zoología de los insectos, arácnidos y crustáceos, designada cátedra de entomología, era la única en Europa a principios del siglo XIX (murió el naturalista en 1829). Para volver al origen de esta institución, es útil recordar que fue durante el reinado de Luis XIII, en enero de 1626, cuando el médico del rey obtuvo la autorización para crear un Jardín real de plantas medicinales, proyecto que se concretó en 1635. Siguió dirigido por médicos del rey y sirviendo exclusivamente de reserva de remedios hasta 1718. También se daban clases de anatomía, botánica y química a los futuros médicos y boticarios. Entre finales del siglo XVII y principios del siglo XVIII ya se fue incitando a los empleados botanistas del Jardín a viajar para recoger nuevos ejemplares de plantas (el padre Plumier viajó a las Antillas, por ejemplo). Después de 1718 y progresivamente, el Jardín se va a tornar Jardín real de plantas e incluso Jardín real a secas, nombre que conservó hasta 1793, o sea cuando se transformó, con la Revolución, en Museo de Historia Natural. Su época de mayor dinamismo, durante el Antiguo régimen, se debió a Buffon, quien lo dirigió durante casi todo el siglo XVIII, de 1739 a 1788. Buffon fue quien creó una red densa de correspondientes por el mundo entero (para poder enriquecer las colecciones y los conocimientos difundidos por la institución). La edad de oro del Museo duró hasta los años 1840 (Duris y Gohau: 42; Pelt: 115) - acerca de las instituciones hispanoamericanas, gabinetes y museos (y también de la institución parisina), así como del coleccionismo, véase el libro colectivo de 
Miruna Achim e Irina Podgorny (eds.) Museos al detalle. Colecciones, antigüedades e historia natural (1790-1870), Rosario, Prohistoria Ediciones, 2013 ${ }^{30}$. A continuación, hablando de las expediciones españolas, se hace referencia a las instituciones españolas y novohispanas.

\section{Principios de la época contemporánea: España, Humboldt y algunos franceses más en México}

A través del testimonio del propio Humboldt, se puede saber algo del dinamismo de la corona española (en tiempos de Carlos III) en Nueva España y en Nueva Granada en cuanto a creación de instituciones y financiamiento de expediciones científicas (Minguet 1979: 70; Del Pino Díaz 1987: 106). Dichas expediciones se habrían desarrollado a consecuencia de la de Godin y La Condamine (véase Esteve Barba: 575-581) y del reconocimiento adquirido por Linneo, lo que dio lugar a la organización de una expedición a la que se asoció uno de sus discípulos, Löfling, en el Orinoco entre 1754 y 1761 (Del Pino Díaz 1987: 108 y ss.), bajo las órdenes del español Iturriaga. En las décadas siguientes, se multiplicaron (Chenu 1993: 113-114).

\section{España y sus expediciones}

Para el continente americano visto desde la perspectiva hispánica, las primeras expediciones oficiales ordenadas por el rey de España fueron llevadas a cabo para estudiar restos de una civilización desaparecida, después del descubrimiento de Palenque a finales del siglo XVIII (Mongne 1987: 12; Demarest: 4647; para más detalles, véase también infra).

Es de sumo interés el Catálogo de las expediciones y viajes científicos españoles, siglos XVIII y XIX de María de los Ángeles Calatayud Arinero (Madrid: CSIC, 1984) ya que identifica y describe todos los archivos disponibles sobre el tema en el Museo Nacional de Ciencias Naturales de España. A más de referirnos los documentos que existen a propósito de la expedición del médico de Felipe II, Francisco Hernández, a la Nueva España, nos permite tener una visión general de las diferentes experiencias llevadas a cabo.

Después de los Siglos de Oro, la primera expedición naturalista española - si dejamos de lado la que dirigieron Löfling e Iturriaga - ocurrió en 1777 y duró hasta 1787, y la integró uno de los correspondientes de Buffon, José Dombey (1742-1794), como acompañante. Se trató de una expedición botánica para estudiar la flora peruana y chilena (lo que incluye un espacio superior al espacio actual de esos dos países, debido a las fronteras de los virreinatos; Calatayud:

30. Reseña de Daniela Serra en Historia, vol. I, n 48, enero-junio de 2015, 333-336. 
25-194). Estuvo dirigida por el botánico Hipólito Ruíz López (1754-1816), quien se llevó a cuatro colegas más y a cuatro dibujantes.

La siguiente la dirigió Félix de Azara (1746-1821). Su estancia en el Río de la Plata duró 20 años (Calatayud: 195-199). Es más conocida, por los historiadores, sin duda por haber tenido un objetivo primordial de orden político, la delimitación de fronteras entre las regiones actuales de Brasil, por un lado, Paraguay, Argentina y Uruguay por el otro (1781-1801), o sea establecer los límites entre posesiones españolas y portuguesas. Sin embargo, se entiende, al leer el descriptivo de documentos, que Azara se interesó mucho en los pájaros y aves y mandó centenares de ejemplares a España (véase también Esteve Barba para más detalles biográficos: 662-667). En efecto, es conocido como naturalista por dos estudios en los que describió algunas especies por primera vez: Apuntamientos para la historia natural de los cuadrúpedos del Paraguay y del Río de la Plata (1802) y Apuntamientos para la historia natural de los pájaros del Paraguay y del

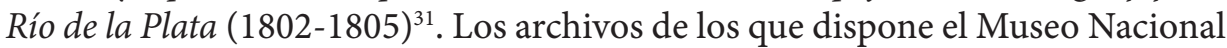
de Ciencias Naturales son pocos, ocupan sólo tres páginas, sin comparación con las 170 páginas de la expedición de Ruiz López (Calatayud: $i ́ d e m$ ).

La tercera expedición estuvo a cargo de José Celestino Mutis (1732-1808), médico y botánico que ya se había instalado en lo que corresponde a la Colombia actual desde 1761 (biografía detallada en Chenu 1993). Se tituló "Expedición botánica al Nuevo Reino de Granada" (¿1783?-¿1810?)” para el estudio de la flora de Bogotá (Calatayud: 201-223). Se dispuso de mayor comodidad a nivel de personal, ya que más de 10 científicos (incluso un economista y dos geógrafos) la compusieron (o participaron en ella), 4 dibujantes y 9 pintores $-\mathrm{y}$ un total de 70 colaboradores después de varias estructuraciones, a eso de 1806 (Chenu 1993: 115-116). Según comenta Jeanne Chenu, con Mutis, la Nueva Granada tuvo que seguir en pocos años un recorrido científico que Europa había hecho en dos siglos, con Copérnico, Kepler, Galileo, Newton y Linneo (Chenu 1987: 248-249). Mutis y sus colaboradores ayudaron bastante a Alejandro de Humboldt cuando pasó por el virreinato y éste hizo a Mutis objeto de la dedicatoria de uno de sus estudios (Chenu 1993: 104). Mutis y su equipo reunieron un herbario de 20000 plantas, con 6400 dibujos (ídem: 117). En la actualidad, el Consejo Superior de Investigaciones Científicas español da acceso, desde la página web del Real Jardín Botánico, a los documentos relacionados con la expedición, y se pueden consultar 7206 dibujos de plantas (http:// www.rjb.csic.es/icones/mutis/paginas/, consultas de marzo de 2018) . En otro

31. Véase también el sitio Biografías y vidas: https://www.biografiasyvidas.com/, buscando por apellido. Consulta del 9 de septiembre de 2016. Según Esteve Barba (664), sus estudios fueron traducidos por Saint-Méry y se publicaron, inicialmente, en francés, en París. 
lugar del sitio, se propone un cuadro que presenta la lista de todos los dibujantes identificados, a más de una serie de explicaciones sobre la expedición y una consecuente bibliografía (http://www.rjb.csic.es/icones/mutis/paginas/ acercadelosdibujos.php).

Hubo también una expedición que tuvo a Filipinas como territorio específico de exploración, dirigida por Juan de Cuellar entre 1785 y 1798, el propósito siendo, como lo era en general en aquella época, proveer en ejemplares las colecciones del Real Gabinete de Historia Natural de Madrid (Calatayud: 225-233).

Hubo otra expedición a Chile y a Perú (Calatayud: 301-315) en los años 1795-1800, integrado sólo por dos hermanos (Heuland), franceses de añadidura, dedicada al estudio de los minerales.

Un poco antes, se dio la "Expedición alrededor del mundo", entre 1789 y 1795 (Calatayud: 275-299), conocida también como "Expedición Malaspina” o "Expedición Malaspina y Bustamante", por el nombre del comandante y jefe de la expedición y su segundo. Viajaron con ellos esencialmente botánicos (3), y 2 dibujantes, a los que se sumaron otros durante el recorrido ( 3 pintores) - en varios buques y una tripulación consecuente. El propósito fue reconocer las costas de América y explorar los mares del sur (Asia y Oceanía: Filipinas, Macao, Cantón, Australia, Nueva Zelandia, etc. $)^{32}$, bajo la inspiración científica de Cook y Lapérouse (Del Pino Díaz 1987: 103) y con propósitos a la vez políticos de balance de la situación del Imperio en sus relaciones con el resto del mundo :

los naturalistas portan una buena colección de pliegos de herbario, algunas muestras mineralógicas, un número nada desdeñable de animales, una colección de materiales etnográficos y, por parte de los dibujantes, se ha realizado un atinado trabajo iconográfico. Casi un millar de imágenes entre plantas, animales, paisajes, tipos etnográficos, ritos y tradiciones... un inmenso álbum de los territorios coloniales, pertenecientes a la Corona española. Sobre todo, se recopiló una amplísima información sobre las relaciones comerciales y el gobierno de la América española (página web del Real Jardín Botánico).

La que interesa más aquí por concernir a México, fue la expedición botánica que dirigió Martín de Sessé (1751-1808) entre 1787 y 1797 (Calatayud: 235273; véase también el artículo muy detallado de Maldonado Polo 2000). Lo acompañaron 3 botánicos y/o médicos más, un naturalista, un farmacéutico y dos pintores. Con uno de ellos, el médico y botánico José Mariano Mociño, redactó Sessé dos obras publicadas póstumamente, Plantae Novae Hispaniae

32. Véase el sitio del Real Jardín Botánico, http://www.rjb.csic.es/jardinbotanico/jardin/index.php?len=\&Pag=92, consultas de abril de 2018. 
(México: Oficina tipográfica de la Secretaría de Fomento, 1893) ${ }^{33}$ y Flora mexicana (México: Oficina tipográfica de la Secretaría de Fomento, 1894) ${ }^{34}$. El propósito de la expedición estaba también relacionado con el de nombrar a Martín de Sessé director del futuro Jardín Botánico de México (según minuta de una carta de 1787 dirigida al Arzobispo de México y Gobernador de Nueva España y un borrador de la Real Cédula que lo nombró en el puesto y a la cabeza de la expedición; véase Calatayud: 237). Se entiende que Sessé dio las primeras clases de botánica en la Real y Pontificia Universidad de México en 1789 (Calatayud: 238 y 240). Se trata esencialmente de un trabajo de recolección de todo lo que existía, animales, plantas y también minerales, así como remitir remedios que explicaciones sobre sus virtudes terapéuticas acompañan (Calatayud: 239 y 242), y por supuesto, dibujos. Todo esto llegaba al Real Gabinete de Historia Natural, al Jardín Botánico y a la Real Botica. Somolinos, el historiador mexicano, insiste mucho en la relación entre el descubrimiento de los manuscritos de Hernández en los años 1780 y la aceptación por la Monarquía del proyecto de Sessé, explicando que el financiamiento de la expedición fue considerado como una manera de completar la obra precursora de Hernández (Somolinos: 177 y ss.; véase también Maldonado Polo 2000: 5-8; Durand-Forest: 62; Puig Samper; Del Pino Díaz 1987 contesta esta hipótesis: 106-107).

Como es de ver, la mayor parte de las expediciones oficiales con objetivos de historia natural (las hubo también con objetivos arqueológicos, véase infra) patrocinadas por España se dio en la segunda parte del siglo XVIII e incluso, en los últimos veinte años del siglo XVIII. La única expedición significativa y oficial de naturalistas, durante el siglo XIX, tuvo lugar mucho más tarde, entre 1862 y 1865. Es conocida como la "Comisión científica al Pacífico" (Calatayud: 319-346). A pesar de su nombre, se trató de viajar por toda América Latina, por la costa y por el interior del subcontinente. Fue una expedición muy importante ya que se trató de recoger un máximo de datos de todo tipo, pero en un periodo difícil para España en sus relaciones con partes del mundo antes colonias suyas (véase el sitio web específicamente dedicado por el Consejo Superior de Investigaciones Científicas español a esa empresa científica, en http://www.pacifico. csic.es/uym3/cntnt/xml/fc03.xml, consulta del 9 de septiembre de 2016):

La Comisión Científica al Pacífico fue la principal empresa científica ultramarina de la España isabelina. En la primavera de 1862 el Ministerio de Fomento decidió agregar un equipo de naturalistas a una escuadrilla naval que un gobierno dirigido por el general O’Donnell, líder de la Unión Liberal, envió a tierras

33. Existe un ejemplar en el Muséum d'Histoire Naturelle de París.

34. Se puede consultar en www.biodiversitylibrary.org, hecho el 13/09/2016. En el año 2010, Siglo XXI de México editó, en 12 volúmenes, la Real Expedición Botánica a Nueva España. Existe una edición del CSIC, publicada en Madrid en 1987. 
americanas en el marco de una política panhispanista. Tras un arduo proceso de selección, el grupo de viajeros naturalistas estuvo formado por seis profesores vinculados al Museo de Ciencias Naturales de Madrid (tres zoólogos, un geólogo, un botánico y un antropólogo) y dos ayudantes: un taxidermista y un dibujante-fotógrafo. Su misión era formar colecciones científicas que enriqueciesen los fondos de los museos españoles y contribuir a desarrollar el programa de aclimatación de animales y vegetales exóticos que fuesen útiles a la economía española. (http://www.pacifico.csic.es/uym3/xml.htm, misma fecha)

Los participantes estuvieron primero en Brasil, el Río de la Plata y Chile. Luego se separaron en dos grupos, uno atravesó por tierra América del Sur desde Montevideo, el otro se fue de barco hacia el Pacífico por el Cabo de Hornos. Después, algunos estuvieron estudiando la botánica peruana y chilena mientras que otros seguían hacia el Norte, hasta California. Hacia 1864 se reunieron en Valparaíso, algunos abandonaron el proyecto, la mayor parte emprendió una tercera etapa, en 1865, desde Quito hasta el Amazonas, hasta embarcar en Pernambuco para volver a Europa (http://www.pacifico.csic.es/uym3/xml.htm, misma fecha). "Como consecuencia de su periplo formaron importantes colecciones zoológicas, botánicas, geológicas, antropológicas y arqueológicas que se custodian en diversas instituciones científicas madrileñas como el Museo Nacional de Ciencias Naturales, el Real Jardín Botánico , el Museo Nacional de Antropología , el Museo de América y el archivo de Marcos Jiménez de la Espada en la Biblioteca General de Humanidades del CSIC." (http://www.pacifico. csic.es/uym3/xml.htm, misma fecha).

En esta última cita, ya se van mencionando algunas de las principales instituciones españolas que promovieron y acogieron los resultados de dichas expediciones - Es de recordar que la creación de un primer Estudio y Gabinete de Historia Natural, en España fecha de 1752 (Llorca; 110; Pimentel: 163-164). Pero no tuvo continuidad más allá de un par de años (Sánchez Almazán) y sólo más tarde, en 1771, fue creado por Carlos III el Real Gabinete de Historia Natural español, que se fundamentó en la entrega de una extensa colección de curiosidades por parte de Pedro Franco Dávila (1711-1786), oriundo de Guayaquil (Pimentel: 149 y ss.; 162 y ss.).

Por el lado mexicano, el Real Jardín Botánico Novohispano fue creado por Sessé a finales del siglo (1786-1787; véase Somolinos: 184 y Maldonado Polo 2000: 6 y ss.; 27-36) y sólo en 1868 fue creada la Sociedad Mexicana de Historia Natural (Vega: 111). Mientras tanto, José Longinos Martínez (1756-1802), naturalista miembro de la expedición de Sessé, instituía en 1790 el Gabinete de Historia Natural (Constantino Ortiz: $\$ 1-7$ y 19), en la ciudad de México, y otro en Guatemala (1796; véase también Maldonado Polo 1994). Vega argumenta en contra de las ideas muy recibidas según las cuales México sufrió de 
un desarrollo científico enclenque debido a la inestabilidad política y se habría limitado, por lo demás, para la época, a un trabajo científico secundario, el de la divulgación. Echa mano de un estudio de la prensa general y de las publicaciones dedicadas a las ciencias naturales a lo largo del siglo XIX y recuerda también la fundación de instituciones, en la capital del país, como el Colegio de Minería, donde se fueron enseñando las ciencias naturales desde los comienzos de la era republicana (Vega: 112-114).

Evidentemente, del mismo modo que resulta difícil dar con datos etnohistóricos, sobre todo comparando con la profusión de datos acerca de las hazañas de las potencias europeas, resulta también difícil saber, por lo menos desde Europa, de las investigaciones llevadas a cabo por españoles de América, a imagen y semejanza del astrónomo neogranadino y discípulo de José Celestino Mutis, Francisco José de Caldas (1768-1816), quien también conoció a Humboldt y, sobre todo, trató de hacer progresar los conocimientos astronómicos gracias a las inmejorables condiciones geográficas del virreinato y a pesar de las pésimas condiciones técnicas (tuvo que fabricarse sus propios instrumentos, cuando pudo, véase Chenu 1987: 252 y ss.). Esto se explica, no tanto por el hecho de que España se haya retrasado en su asimilación de las innovaciones e ideas de Linneo, Buffon y demás discípulos y continuadores (Aguilar: 73), más bien se debió al retraso con que se publicaron y difundieron (o se debió a la ausencia de publicación y/o difusión) los trabajos de exploración e inventario (Clément 1993, "Des noms de plantes au XVIII siècle": 86-91).

\section{Los grandes viajeros naturalistas de principios del siglo XIX: Humboldt, Bonpland y d'Orbigny}

Los grandes viajeros botanistas y geógrafos, los muy conocidos, Alejandro de Humboldt, su compañero de viajes y colaborador científico, Aimé Bonpland, y también Alcide d'Orbigny, son bien conocidos, sea por todos, sea al menos, por los especialistas de las ciencias naturales y por los latinoamericanistas, incluso los literarios - ya que esos personajes aparecen a veces en novelas de tema histórico. Es el caso del francés Aimé Bonpland, retratado en la novela de Augusto Roa Bastos, Yo el Supremo (1974), aunque de modo algo enrevesado a través del discurso irónico atribuido al personaje José Gaspar Rodríguez de Francia, el ilustrado dictador que dirigió la joven república de Paraguay en la primera mitad del siglo XIX, en torno a quien se organiza la ficción narrativa.

Alejandro de Humboldt (1769-1859) ha sido objeto de un sinfín de estudios porque también su obra fue monumental - y el reconocimiento de la envergadura de su obra inmediato y masivo (Dugast). La describe con una precisión y un esmero renovados Charles Minguet en su estudio de 1969, Alexandre de Humboldt. Historien et géographe de l'Amérique espagnole (1799-1804), poco tiempo después 
de los importantes estudios que se le dedicaron en México, con Rayfred Lionel Stevens-Middleton, La obra de Alexander von Humboldt en México (1956), Juan A. Ortega, Humboldt desde México (1960) y J. Miranda, Humboldt y México (1962), así como un conjunto de Ensayos sobre Humboldt en la misma década (Minguet: 19) ${ }^{35}$. La obra de Humboldt es famosa por el interés que puso el estudioso europeo en conocer toda la variedad de realidades físicas y naturales de América ${ }^{36}$. De la Venezuela actual, adonde llegó a finales de 1799 (a Cumaná), fue bajando hacia el sur, haciendo un viaje de ida y vuelta en el interior de la región del Orinoco hasta cerca del Río Negro (zona de contacto entre los actuales territorios de Colombia, Venezuela y Brasil). Luego viajó (o más bien viajaron, él y, por lo menos, su compañero Aimé Bonpland) a Cuba (1800), de ahí a Cartagena de Indias (1801), desde donde se internaron en el virreinato de Nueva Granada atravesándola de norte a sur hasta llegar a Lima (cruzando la Colombia, el Ecuador y el Perú actuales), antes de tomar un barco que los llevó a Acapulco, desde donde se internaron en el centro del territorio mexicano actual hasta cerca de Guanajuato, al norte y Veracruz al este, entre 1803 y 1804. De ahí Humboldt volvió a Cuba, de Cuba a Estados Unidos, y de Estados Unidos su viaje de regreso a Europa lo dejó en Burdeos (Minguet: 20-22, mapas; Tulard: 28, mapa; Pinault Sorensen: 199-201).

Esta serie de viajes dio lugar a la publicación de una obra escrita con Aimé Bonpland, en francés, de 30 volúmenes, bajo el título de Voyage aux régions équinoxiales du Nouveau Continent, fait en 1799, 1800... 1804 (1807-1834) $)^{37}$. Al recorrer los índices de los diversos tomos de la obra, se entiende claramente por qué se ha podido hablar, acerca de estas exploraciones, de segundo descubrimiento de América (Potelet y Farré: 8). El mismo Humboldt tuvo esa pretensión, ya que explica en su introducción general que quiere dar a conocer esas tierras a los europeos y a la misma España (Humboldt 1826 tomo I: III).

35. El estudio de Ortega aborda, más específicamente, el impacto de Humboldt en la cultura mexicana de los siglos XIX y XX. El de Stevens-Middleton es una precisa descripción de la obra del sabio alemán, el Ensayo Político sobre el reino de Nueva España. 36. Véase una breve síntesis de este recorrido y sus objetivos en Pedro S. Urquijo Torres, Humboldt y el Jorullo. Historia de una exploración. México: UNAM, 2008: 48-57.

37. Se dispone de una edición original de la obra (París: F. Schoell, 1805-1834) en la Biblioteca Universitaria de Ciencias y Técnicas de Burdeos, en el departamento de documentos antiguos. En el sitio de la Biodiversity Heritage Library, sólo se puede consultar el tomo tercero de la Primera parte, en una edición alemana de 1970, con el texto original, en francés (https://www.biodiversitylibrary.org/item/95419\#page/1/mode/1up, consultas de marzo 2018), varias versiones vertidas al inglés y al alemán, así como algunos tomos en español (los tomos I a V, impresos en París en 1826 por Rosa (Imprenta Pochard); véase tomo I : https://www.biodiversitylibrary.org/item/76266\#page/1/mode/lup, mismas fechas de consulta). 
Humboldt tocó todas las disciplinas o futuras disciplinas relacionadas con las ciencias de la tierra (geología, geofísica, geografía), las ciencias naturales (botánica, fisiología, zoología) y las ciencias del hombre (Minguet 1969: 548 y ss.; Castrillón: 220). Minguet evoca la importancia capital de sus aportes a la climatología y a la meteorología (con las líneas isotérmicas, Minguet 1969: 562 y ss.), así como a la oceanografía (ídem: 575 y ss.). Incluso escribió sobre Centroamérica, reconociendo que nunca había pisado esa región pero citando con espíritu enciclopédico y capacidad de síntesis descomunal el conjunto de las fuentes que le permitieron escribir al respecto (Humboldt, Centroamérica: 41-42). Sobre México, escribió el famoso Essai politique sur le royaume de la Nouvelle-Espagne (1811), que ha sido un modelo fundador de los estudios de geografía regional americana (Minguet, artículo "Humboldt"). Sobre botánica y geografía, el Essai sur la géographie des plantes (París: Levrault, Schoell y compañía, 1805) ${ }^{38}$; así como una obra más impregnada de romanticismo, Tableaux de la nature (primero en alemán en 1808, luego en una nueva versión de 1826, traducida en francés y publicada en París: Gide fils, 1828) ; en un prefacio el autor dedica sus descripciones de paisajes a las almas desdichadas y a menudo se maravilla de lo que ofrece la naturaleza ${ }^{39}$.

Acerca de las culturas indoamericanas y sus vestigios, publicó en 1810 Vues des Cordillères et Monuments des Peuples Indigènes de l'Amérique con varias ilustraciones (Duviols 1993: 189-190; Humboldt 1824), libro en el que se interesa en la escritura, las lenguas, el cómputo del tiempo, la arquitectura, etc., principalmente entre los pueblos mexicanos y los peruanos. Acerca de Cuba, fue el Essai politique sur l'île de Cuba, proporcionando datos y análisis de interés geográfico, histórico, sociológico, económico, etc. (Duviols 1993: 190-191 y 195-196).

Con Aimé Bonpland trajeron de América unas 5800 especies de plantas, entre las cuales 3600 desconocidas hasta la fecha (Minguet 1969: 571). Humboldt es también conocido por haber corregido algunos errores de Buffon en la descripción de los habitantes autóctonos de América, insistiendo en la variedad de características físicas y culturales y demostrando el origen asiático de dichas poblaciones (Minguet, artículo "Humboldt"). Para Manuel Maldonado-Koerdell, fueron Humboldt y sus obras quienes suscitaron el interés de viajeros naturalistas por México, y el país habría conocido una "edad de oro" al respecto, durante la primera mitad del siglo XIX (Maldonado-Koerdell: 98-99). Según Duviols, el trabajo de Humboldt suscitó el interés de Europa por todo el

38. Véase http://www.biodiversitylibrary.org/item/37872\#page/3/mode/1up, consulta del 13/09/2016.

39. Véase http://www.biodiversitylibrary.org/title/40042\#page/7/mode/1up 13/09/2016. 
continente americano, en particular por su naturaleza y sus culturas (Duviols 1993: 185-188).

Aimé Bonpland (1773-1858), su incondicional colaborador, era hijo de médico y médico él mismo, fue alumno de Jussieu (Antoine-Laurent, 1748-1836, sobrino de los tres Antoine, Bernard y Joseph) y Lamarck en el Jardín real y Museo de Historia Natural de París. Se topó con Humboldt en 1796 y después de una estancia en España salieron rumbo a América en 1799. Volvió a América, al Río de la Plata, después de la caída de Napoleón, y terminó viviendo en Paraguay (por intención propia o forzado, según las circunstancias) y siguió mandando al Museo de Historia Natural miles de plantas desconocidas en Europa (para más detalles, Deschamps y Maroussy: 113-118; Allorge y Ikor : 640641; Trystram).

Alcide Dessalines d'Orbigny (1802-1857) viajó por América entre 1826 y 1834 (Philippon). Fue un geólogo y sobre todo uno de los primeros paleontólogos, el primero del Museo de Historia Natural de París (1857). Publicó desde los años 1830 una serie de relatos acerca de sus viajes, como el Voyage dans l'Amérique méridionale: (le Brésil, la république orientale de l'Uruguay, la République argentine, la Patagonie, la république du Chili, la république de Bolivia, la république du Pérou), exécuté pendant les années 1826, 1827, 1828, 1829, 1830 $(1847)^{40}$ [Brygoo : 263] y el Voyage pittoresque dans les deux Amériques (1836) [Laborde-Pédelahore y Boone: 250]. La importancia del contexto científico en torno a las instituciones parisinas se percibe en su formación y evolución al ver que tenía contactos con Cuvier, los Brongniart y el mismo Humboldt (idem). Pero también tuvo su importancia el origen familiar - su padre era médico y aficionado a la historia natural (Brygoo: 261-262). El Muséum d'Histoire Naturelle lo designó como "viajero naturalista" desde muy joven y así se fue a investigar en América del Sur desde 1826 (ídem). Anduvo por el subcontinente durante casi 8 años que lo llevaron, incluso, a trabajar para el estado boliviano como cartógrafo y geólogo (Brygoo: 263).

A pesar de las especialidades que se le reconocen, al hojear su Viaje a la América meridional se percibe el interés enciclopédico de este científico, cuya curiosidad parece haber tenido el mismo tamaño que la de Humboldt ya que, bajo la forma de un diario (o sea con fechas regulares y cronológicamente crecientes), va contando el autor todo lo que le pasa y que observa: las plantas, los animales, los paisajes, las costumbres, el trabajo del campo, las ciudades, las luchas políticas, las tensiones entre nuevas naciones del sur de América, etc., extendiendo su relato cronológico de sus viajes en esos siete tomos de varios

40. Son 7 tomos publicados entre 1834 y 1847. Se pueden consultar en el sitio de la Biodiversity Heritage Library: https://www.biodiversitylibrary.org/bibliography/85973\#/ summary; últimas consultas en mayo de 2018. Véase también Boulinier: 280. 
centenares de páginas - hubo colaboradores, sin embargo, para detallar toda la fauna suramericana (véase Brygoo: 264-265). Para dar algunos ejemplos, insectos, recogió como 4000; moluscos, 243 especies, 1500 pájaros y aves (véase Brygoo: 265-270, para el detalle de todas las categorías animales).

Aunque conoció muchas dificultades en encontrar un puesto en el Muséum, entre les profesores de la institución, una vez terminado su viaje (Brygoo: 271271), es de saber que él y Darwin fueron rivales directos (véase todo el artículo de Boulinier al respecto). Su colega británico anduvo también viajando por el Cono Sur - Uruguay y Argentina actuales, en particular -, aunque la duración de su estancia en América del Sur, como miembro de la expedición del Beagle, haya sido más breve de unos dos años (Boulinier: 279-280). Y una gran parte de sus libros se refieren a sus exploraciones científicas en terreno suramericano (ídem: 283). La rivalidad entre ellos fue terrible, a lo parece (ídem: 289; véase también Laurent: 292 y ss.). A través de ellos, grandes naciones hegemónicas (Francia, Gran Bretaña) iban compitiendo en el mercado científico y cultural (o sea simbólico, diría un adepto de Bourdieu; para "la gloria de su Majestad y de toda la nación" decía Mutis al rey de España a propósito de su trabajo en su correspondencia de finales del siglo XVIII, véase Del Pino Díaz 1987: 116) en base a la explotación del patrimonio natural y paleontológico suramericano ${ }^{41}$.

\section{Reflexiones sobre los libros: de naturalistas y de viajes}

No hay dudas en cuanto a la influencia de la obra de Humboldt y Bonpland. Basta con observar el hecho de que las obras de Sessé y Mociño sólo salieron a la imprenta un siglo después de sus viajes, observaciones y recolecciones por Nueva España. Es que esas dos obras, además, no son relatos, no tienen el carácter ameno y comunicativo de la narración, sino que se trata de una enumeración clasificada de nombres y características botánicas, en estilo telegráfico y, por añadidura, en latín. La impresión producida es la de ir leyendo un diccionario. Y ni siquiera se encuentra un dibujo en, por ejemplo, Flora mexicana (a la inversa, del trabajo de Mutis y sus colaboradores sobre la flora de Nueva Granada, sólo llegaron hasta nosotros los dibujos : http://www.rjb. csic.es/icones/mutis/paginas/acercadelosdibujos.php, consultas de febrero y marzo de 2018). O sea que estas obras son ilegibles para un público profano,

41. El interés renovado por esta figura del naturalismo decimonónico se puede percibir en algunas publicaciones recientes que le fueron dedicadas: Daniel Dory, Christian Moreau (eds.). Alcide d'Orbigny, entre Europe et Amérique : textes et contextes d'une cuvre: actes du colloque, Université de La Rochelle, 18-20 avril 2002. Rennes : Presses universitaires de Rennes 2005 ; Françoise Legre-Zaidline, Alcide Dessalines d'Orbigny (1802-1857), París: L'Harmattan, 2002; Philippe de Laborde Pedelahore, Alcide d'Orbig$n y:$ à la découverte des nouvelles républiques sud-américaines, Biarrtitz: Atlantica, 2000. 
aunque curioso (http://www.biodiversitylibrary.org/item/8992\#page/37/mode/1up, consulta del 13/09/2016). Incluso la primera versión de la clasificación de Carlos Linneo, de 1735, alterna partes redactadas con partes que consisten en cuadros clasificatorios, muy cuidados que, por esa alternancia y cualidad estética, atraen la vista y el interés intelectual (http://www.biodiversitylibrary.org/ title/877\#page/12/mode/1up, misma fecha de consulta). En cambio, la obra de Sessé se parece ya mucho más a ediciones posteriores del Sistema naturae, con su dimensión casi puramente enumerativa (véase la de 1894 que copia la décima, de 1758, que consta de unas 830 páginas: http://www.biodiversitylibrary. org/title/35518\#page/62/mode/1up, misma fecha).

Basta con comparar lo que trató de hacer e hizo Linneo con lo que propuso Buffon para entender estas diferencias y también su enemistad. Mientras que el primero iba volviendo su sistema de clasificación cada vez más cohesivo y, por lo tanto, más codificado y técnico (emancipándose cada vez más, conforme iba perfeccionando su sistema, de la sintaxis del lenguaje ordinario), Buffon iba reflexionando, citando, incluso contando anécdotas tomadas de diversos autores, y proponiendo analogías o relaciones familiares a veces certeras, a veces insensatas. Es una lectura muchísimo más llevadera la de su obra, más humanística se podría decir, y también más divertida. Cuando trata de aves, siempre compara las europeas con las "extranjeras" que podrían relacionarse con ellas, y cuando llega el subcapítulo dedicado al cóndor (Buffon 1829, tomo XIX: 162-169), por ejemplo, en primer lugar es de señalar que cita sus fuentes, mencionando a los autores que consultó (el padre Feuillée, Frézier, d'Abbeville, Acosta, Garcilaso; ídem: 165; luego Desmarchais y algunos más). A veces, lo hace de modo bastante extenso - del padre Feuillée cita todo un relato acerca de cómo hizo el viajero naturalista para herir un espécimen, capturarlo y llevárselo para dibujarlo (ídem: 162-164). En segundo lugar, Buffon guarda, del relato de Feuillée, la descripción física pormenorizada del ave y de sus hábitos (164-165). Por fin, Buffon hace hipótesis en base a datos no muy fidedignos, a pesar de su explícito escepticismo respecto a algunas de sus fuentes, terminando por relacionar la famosa ave andina con otras mucho más fabulosas (por la inverosimilitud de sus dotes), de África y de India, capaces de levantar elefantes entre sus garras. Termina el capítulo acumulando anécdotas sobre la fuerza de esas aves, hasta tal punto que confieren a su tratado los mismos encantos que los gabinetes de curiosidades en los que se empezó por coleccionar los objetos naturales más extraños y no los más representativos de la realidad animal y mineral. Estos rasgos, la dimensión compilatoria, la invocación de autoridades y la índole a veces sobrenatural de los hechos y seres descritos delatan una relación todavía muy fuerte de la escritura científica de Buffon con la Edad Media y la Edad Moderna (a la que pertenece). 
El libro de Humboldt dedicado a México, Essai politique sur le royaume de la Nouvelle-Espagne, aunque no presente una dimensión subjetiva muy marcada al modo típicamente romántico es, sin embargo, un relato que incluye datos, pero que son datos que se relacionan más con lo que hoy se llamarían las ciencias humanas y sociales (geografía, demografía, historia, sociología y economía con elementos de cálculo astronómico y de observaciones geológicas, mineralógicas, climáticas, agronómicas). Como conjunto, da la impresión de que se va leyendo un ensayo muy bien documentado, con muy frecuentes referencias a demás autores y exploradores (Humboldt incluso cita las libretas de apuntes de ingenieros españoles, véase las páginas 75-76 en la edición de 1811: http://www. biodiversitylibrary.org/title/95434\#page/85/mode/1up, consulta del 13 de septiembre de 2016; se trata de la segunda edición del tomo I del Ensayo, publicada en París por Antoine-Augustin Renouard en 1825), que es el género literario señalado en el título. Pero el primer capítulo dedicado al cálculo de la posición geográfica de las principales ciudades de Nueva España parece muy riguroso; presenta, también, una tecnicidad movediza pero innegable (medidas, cálculos y comparaciones de medidas de longitud y latitud; a partir de la página 176, aparecen cuadros en los que se proporcionan los datos para localizar las ciudades, la altura de las montañas y volcanes, etc.).

Como escritores científicos (Duviols 1993: 184 y ss.), Humboldt y Bonpland publicaron varios libros y constituyeron numerosas colecciones - a las que se refiere Humboldt en su introducción al Viaje a las regiones equinocciales. A eso de la página XLIX de dicha introducción, y en las páginas siguientes, problematiza el autor la cuestión de la forma de las obras y el horizonte de expectativas de los lectores. Para ello, establece una clara diferencia entre sus obras anteriores al Viaje a las regiones equinocciales, que es, en versión original, una Relación histórica del viaje...y este libro en el que dice que se dejó convencer por el interés de contar la historia de esas exploraciones científicas. Pero trata de disculparse por no haber mantenido la orientación narrativa constante y por haber sustituido, a veces, la relación por la descripción de datos (véase Humboldt 1826, tomo I: LV-LVI). Esta problematización señala las funciones algo divergentes que han podido asumir, por un lado, estudios muy pormenorizados en cuanto a cuestiones técnicas, y eso desde los tratados sobre lenguas o cómputo temporal, de los soldados y misioneros autores de crónicas y demás estudios sobre América, y los relatos de viajes que pretenden proporcionar, a priori, datos de todo tipo y poco profundizados, acerca de los territorios transitados. Unos pueden ser leídos por especialistas, los otros por un público lector mucho más amplio, como si se tratara de obras de divulgación. No es lo mismo contar que se vio tal flor o tal árbol en tal lugar, acompañando esto con una breve descripción y proponer una clasificación de dichos ejemplares o describir de modo pormenorizado 
dichos ejemplares. Semejante diferencia expresa Pierre Vayssière al decir que el género de los libros de viajes es mixto y que se sitúa entre el "journal de voyage au jour le jour et l'oeuvre scientifique méthodiquement construite" (Vayssière: 255). Es también la diferencia que hacía el naturalista Auguste de Saint-Hilaire respecto a sus publicaciones sacadas de sus exploraciones por Brasil: clasificaciones botánicas por un lado, relatos de viajes por el otro, con datos más variados (sobre geografía, agricultura, comercio, etc.; véase Kury 2011: 165-168), de "natureza compósita e interdisciplinar de textos cruzados pela Literatura, História e Antropologia" (Cristóvão, "Inntrodução. Para uma teoría da Literatura de Viagens", 16).

En el mismo sentido pero como forma de diferenciación dentro de la categoría Literatura de viajes, los editores de la Histoire générale des voyages (17461789) del abate Prevost, hicieron por distinguir entre dos clases de contenido: "una cosa era el diario del viaje, la peripecia del cómo llegaron y por dónde pasaron los viajeros, y otra la historia natural del lugar, las costumbres de sus habitantes, sus producciones y comercio." (Pimentel: 233) Desde los principios de la Edad Moderna se produjo un arranque comercial significativo en el sector de la literatura de viajes que se mantuvo hasta el periodo contemporáneo (Cristóvão, “Introdução...”: 26 y ss.). Como lo evidencian los títulos a veces larguísimos y descriptivamente muy detallados, se trataba para el viajero y explorador de contar todo lo que había visto (ídem: 30-34) y fuera digno de despertar la curiosidad del lector (que el editor hacía por estimular de esta forma): "É que os relatos de aventuras e de desvendamento [revelación] do desconhecido eran tão do agrado do homem renascentista, como do ciudadão do século das Luzes." (32) Y, sin duda la variedad de contenido de esta literatura contribuyó y contribuye todavía en atraer a los lectores: "Entre los géneros y tipos de textos integrados en el relato de viajes se hallan: el diario y la estadística, el material gráfico y cartográfico, el tratado político y la narración literaria, el ensayo filosófico y el comentario científico, la leyenda y la autobiografía, además del tratado geográfico y del estudio de campo etnográfico. Todos estos tipos de texto se pueden encontrar también en la novela." (Ette: 27). Esta mezcla de ingredientes, de disciplinas poco o nada institucionalizadas y diferenciadas hasta entrado el siglo XIX, contribuyó en la difusión de una cultura científica o, digamos, en la difusión ampliada de conocimientos, y en la apertura cosmopolita del horizonte cultural europeo, porque:

Más o menos erudita, más o menos docta, lo cierto es que la ciencia desplegada en los relatos de viajes supo envolver una narrativa que hablaba a sus contemporáneos de la expansión europea bajo unos términos filosóficos que poco tenían que ver con antiguas gestas y conquistas. La nueva épica quiso ser filantrópica y movida por la curiosidad. Se desplegaba sobre las especies naturales y enlazaba 
rápidamente con otros temas muy en boga en el pensamiento de la época, caso de la idea del progreso, la sociabilidad, el origen de la civilización o la diversidad cultural (Pimentel: 245).

\section{Viajes y viajeros por tierras mexicanas (siglo XIX): el interés por lo arqueológico antes que por la naturaleza}

En cuanto a Mesoamérica y México en particular, también se han publicado trabajos y se conocen, como lo recuerdan Mario Ruz y Eréndira Peniche García (Ruz y García: 12), los relatos de autores que se interesaron en la península de Yucatán. Según Mario Ruz, se ha oscilado, en el siglo XIX, "entre la información científica y la descripción romántica" en los escritos de los viajeros que transitaron por esa región. Y esta visión elaborada por viajeros extranjeros en su mayoría, parece haber sido la que permitió a los mexicanos hacerse una idea de su propio país (Ruz y García: 14), porque pocos eran los mexicanos que viajaban por ocio o interés de conocer en la época, y todavía menos fueron los que dejaron algún escrito (idem: 15). De manera más general, incluso, se puede considerar que los ilustrados mexicanos establecieron contactos con la ciencia europea mediante su relación con los miembros de las expediciones científicas (Maldonado Polo 2000: 9-10).

Como puede que no salte a la vista por los títulos a menudo bastantes generales o alusivos de las publicaciones, las obras de estos autores, entre los más conocidos, versaban sobre arqueología o, digamos que sus autores fueron precursores de la arqueología mexicana. Se interesaron en las ruinas mayas, aztecas y de demás culturas de Mesoamérica.

Jean-Frédéric Waldeck (1766-1875) fue el autor de Voyage pittoresque et archéologique dans la province d'Yucatan (Amérique central), pendant les années 1834 et 1836 (París: Bellizard-Dufour et Cie, 1838). Carolina Depetris le ha dedicado un estudio pormenorizado (2014) en el que se ponen de realce varios defectos que explican el que su libro haya sido ignorado a partir de la publicación de los de Stephens y Catherwood. El estadounidense John Lloyd Stephens (1805-1852), precisamente, con la ayuda del ilustrador británico Frederick Catherwood, fue el autor de Incidents of Travel in Central America, Chiapas and Yucatán (New York: Harper, 1841) así como de Incidents of Travel in Yucatán (New York: Harper, 1843). Son las obras más significativas del siglo XIX por su difusión y éxito. En el capítulo dedicado a la civilización maya antigua de su famoso ensayo, Collapse. How Societies Chose to Fail or Succeed (2005), Jared Diamond se refiere inmediatamente a estas obras de Stephens y Catherwood para evocar el redescubrimiento de las ruinas (versión francesa: Effondrement: 247-248 y 827$)$. 
En realidad, no se trata de ninguna novedad lo que "descubrieron" Stephens y Catherwood: se fue explorando e informando acerca de ciudades abandonadas y ruinas antiguas desde el siglo XVIII y a lo largo del siglo XIX, un trabajo hecho por funcionarios reales y coloniales (Demarest: 46-47). Lo que sí lograron hacer Stephens y Catherwood fue llamarle la atención a un público amplio sobre estas realidades culturales. Así es como en 1785, el arquitecto del rey de España, Antonio Bernasconi, viajó a Palenque para alzar el plan de la ciudad mesoamericana. Esa fue la segunda expedición a Palenque, la primera ocurrió el año anterior, también a petición de Carlos III (Depetris 2014: 9 y siguientes). Unos años después, le tocó al capitán del Río hacer el viaje con un ilustrador, Ricardo Almendáriz. En 1807-1808, llegaría la vez del capitán Guillermo Dupaix con el pintor José Luciano Castañeda, en otra expedición oficial por México y América Central. Luego le tocaría a Juan Galindo (como gobernador del Petén) explorar, en los años 1830, varios vestigios mayas. Estos dibujos y relatos se publicaron en periódicos europeos y en libros populares de amplia divulgación como los del viajero francés Jean-Frederic Waldeck (Demarest: 47). De todos modos, Waldeck también ya había estado y escrito y sacado dibujos sobre Palenque y Uxmal (Depetris 2014: 9-24). Lo que es más digno de comentarios, como lo señala ella y que constituye el eje de su estudio, es la manera de representarse a los mayas que adoptó Waldeck (relacionándolos con civilizaciones de Oriente, etc.; véase Depetris 2014: 24 y siguientes).

De manera general, como ya se dijo, los vestigios suplantaron la naturaleza desde el punto de vista del interés que llegaron a suscitar a lo largo del siglo XIX, interés por el pasado ilustre de las culturas locales. A continuación se propondrán algunas ilustraciones de ello, con el caso de Désiré Charnay, por un lado, y el de varios ingenieros por el otro. Los condicionantes de estos intereses contrarios tendrán que haber sido el desarrollo industrial de Europa, en el segundo caso, en busca de nuevas riquezas naturales que captar y transformar; $y$, en el primer caso, esa múltiple necesidad e interés en reconocer la diversidad humana y sus legítimas y genuinas producciones culturales, así como reivindicar, en una base tanto más legítima cuanto más distante en el tiempo (a imagen y semejanza de la Antigüedad mediterránea) las raíces culturales de las nuevas naciones - es de recordar que esta tendencia en interesarse mucho en los vestigios y culturas antiguas se iba dando también en Egipto y Mesopotamia (Demarest: 48).

Antes, es imprescindible citar, por lo menos, a otros dos viajeros que anduvieron también por México: el naturalista Pierre-Marie Arthur Morelet (18091892), primeramente autor de varios libros acerca de moluscos fluviales de 
Portugal y sus pertenencias de ultramar, en particular en África ${ }^{42}$, encargados por la corona portuguesa, en la perspectiva de sacar provecho de los recursos naturales de ciertas colonias como Guinea y Angola; lo declara tan sencillamente el autor al principio de una de sus obras (Description des mollusques terrestres et fluviatiles $d u$ Portugal, 1-2. ${ }^{43}$. Aparecen la geografía, las ciencias físicas y naturales como medios de hacer medrar el presupuesto de un gobierno. Pero Morelet también fue el autor de un relato de viaje acerca de una expedición a Mesoamérica llevada a cabo para el Museo de Historia Natural de París, Voyage dans l'Amérique Centrale. Lî̀le de Cuba et le Yucatán (París: Gide et Baudry, 1857). Otro caso relativamente conocido de visitantes a las tierras mayas fue el de Alice Dixon Le Plongeon (1851-1910), viajera inglesa y autora de un conjunto de relatos publicados en la prensa y reunidos bajo el título de Here and there in Yucatan (Nueva York: John Lowell, ¿1879 o 1899?). Se la asocia (o, por lo menos su marido, Augustus) a Charnay como representante de la clase de los gentlemen (y women) viajeros que elucubraron interpretaciones fantasiosas acerca de la cultura maya (Demarest: 48) y propusieron una visión idealizada y utópica de Yucatán (España Paredes: 185; 190 y ss. acerca del vínculo establecido entre Yucatán y la mítica Atlántida). En el caso de Le Plongeon, incluso se ha hablado de "exotismo primitivista" inspirado en el mito del buen salvaje (ídem: 190).

\section{El caso de Desiré Charnay}

Otro gran viajero que anduvo por una gran parte de México y también por la península yucateca fue el francés Désiré Charnay (1828-1915). Su primer relato de viaje (Le Mexique 1858-1861. Souvenirs et impressions de voyage, 1863) consiste en descripciones de toda índole, desde consideraciones sobre los paisajes y los animales hasta comentarios sociológicos y también, a veces, políticos. Lo que llama la atención es la amplitud de los temas que aborda y, a la vez, el aspecto superficial de sus observaciones. Su relato tiene ese rasgo, el de yuxtaponer temas tratados en muy pocas líneas y tan variados que escasas veces profundiza en un tema. Cuando lo hace, puede incurrir también en estereotipos (sobre la diferencia de humor entre el Indio y el Negro, Charnay: 190), o sea en comentarios muy trillados ya en la época en que escribía, por ejemplo, acerca de los habitantes de México (Charnay: 100 y siguientes) - piénsese en las novelas de Lizardi.

Cuando comenta las características del paisaje y de la tierra en la península yucateca, resulta muy pobre lo que él alcanza a decir (Charnay:188-189), sobre

42. Consúltese el sitio del SUDOC, http://www.sudoc.abes.fr, repertorio bibliográfico de las bibliotecas universitarias francesas.

43. Véase, más precisamente: https://books.google.fr/books?id=UScHAQAAIAA$\mathrm{J} \&$ printsec $=$ frontcover\&hl $=$ fr\&source $=\mathrm{gbs} \_$ViewAPI\&redir_sc $=\mathrm{y} \# \mathrm{v}=$ onepage\&q\&f$=-$ false, consulta de septiembre de 2016. 
todo comparado con lo que Diego de Landa había escrito varios siglos antes y que se estaba a punto de conocer gracias al trabajo de un abad francés, Charles-Etienne Brasseur de Bourbourg (1814-1874) quien había ido a investigar en los archivos españoles, lo que lo llevó a hacer publicar la Relación de las cosas de Yucatán (de 1566) en 1864 (Demarest: 49) y también, anteriormente, el Popol Vuh (según dice el propio Charnay 1987: 208) ${ }^{44}$. Fue éste el autor del estudio titulado Recherche sur les ruines de Palenque et sur les origines de la civilisation du Mexique (París, Bertrand, 1866). Sin embargo, Charnay le dedica un breve apartado a la milpa y a la técnica de la quemazón (o roza-tumba-quema; Charnay 1987: 199-200). A Charnay se le ocurrió viajar a México a consecuencia de su lectura de las obras de Stephens y Catherwood con las que se topó cuando, joven de poco más de 20 años, se empleaba como profesor en un colegio de la Nueva Orleans dando clases de francés (Mongne: 24).

Es posible que el aspecto superficial de sus apuntes se deba, en parte, a las condiciones en las cuales anduvo viajando por México: el país conocía un periodo de inestabilidad política y de inseguridad muy fuerte, y el pobre viajero perdió varias veces su material e incluso, fue sospechado de espionaje por un grupo de soldados, a consecuencia de lo cual vio destruidos sus primeros apuntes y clisés fotográficos, fruto de su primer año de estancia en el país (Mongne: 25-26). Una explicación quizá convincente se la puede intuir al leer de modo contrastivo su primer libro al que nos hemos referido (de 1863, también conocido con el título de Cités et ruines américaines; véase Mongne: 71-72) y una versión de sus viajes por México y la región de Yucatán, en particular, "Mis descubrimientos en México y en la América Central", que corresponde a exploraciones llevadas a cabo en los años 1880 (o sea que debería corresponder al contenido de Les Anciennes villes du Nouveau Monde, publicado en 1885), pero que fue publicado en español en Barcelona en 1884 (véase bibliografía). El propio explorador lo reconoce desde las primeras páginas de la obra publicada en esta miscelánea catalana titulada América pintoresca. Descripción de viajes al Nuevo Continente (que también contiene textos de otros viajeros franceses, Charles Wiener, Jules Crévaux y Edouard André), cuando escribió la primera, era joven y sus conocimientos eran pocos (Charnay 1884: 265-266). Efectivamente, la cualidad del estudio publicado en Barcelona en 1884 es muy superior en cuanto a análisis y comentarios, así como a referencias históricas a la literatura de las crónicas y demás obras del siglo XVI convocadas para elaborar consideraciones

44. En efecto, existe una edición de 1861 del libro maya quiché publicado en París por el editor Bertrand. Es una edición bilingüe. En las bibliotecas universitarias, hay tres ejemplares del libro, en Estrasburgo, Lyon y París. También viajó Bourbourg, y no sólo a visitar los archivos españoles, sino también por México y por América Central; tiene publicado, por ejemplo, un Viaje por el istmo de Tehuantepec (1859-1860). 
sobre aspectos arqueológicos y demás. Por ejemplo, cita muy a menudo a Diego de Landa, entre otros grandes autores de la época moderna (Villegas: 161).

A pesar de todo, la novedad y el aporte de Charnay para su tiempo fue publicar un trabajo de descripción de ruinas mexicanas apoyado en fotografías que él mismo había tomado. Tuvo un éxito inmediato en Francia y se tradujo en inglés y en español (Mongne: 28) ${ }^{45}$. Consiguió ir a México varias veces a continuación, siguiendo con su interés por las ruinas y visitando todos los grandes sitios y haciendo fotos y moldes. A pesar de no haber sido un arqueólogo de ley tales como los que empezaron a aparecer a finales del siglo XIX (aplicando técnicas de estratigrafía), se le debe reconocer un papel de pionero y algunas intuiciones desde entonces confirmadas.

\section{Ingenieros y naturalistas después de Humboldt}

Al lado de las excavaciones y búsquedas de ruinas de templos y ciudades, también fueron redactados y publicados estudios descriptivos sobre mineralogía y geología, por parte de ingenieros y demás expertos de la extracción minera que estuvieron trabajando algunos años en México. En cierta medida, en este caso también, siguieron el camino abierto por el propio Humboldt. Estos estudios son casi desconocidos (Maldonado-Koerdell: 106), quizá porque fueron publicados en los países de origen de los viajeros y, sin duda, por su índole más técnica que lo escrito por los viajeros exploradores más conocidos.

Sin embargo, si observamos (con Pierre Moret) quiénes, entre los naturalistas franceses -franceses porque nos han resultado más asequibles los datos desde Francia - viajaron a México, aparecen pocos, la mayor parte habiendo viajado más bien a Brasil, al Río de la Plata y a Colombia. Por lo menos son pocos entre los 53 naturalistas de lengua francesa (franceses y suizos) que toma en cuenta Moret en su síntesis de la labor llevada a cabo en cuanto a insectos en América del sur entre 1815 y 1914. Uno de ellos fue Auguste Sallé, un viajero y comerciante que practicó la zoología en general, en tierras mexicanas pero también venezolanas y caribeñas, entre 1832 y 1860. Reunió un número considerable de elementos en sus colecciones (Moret: 398). Henri de Saussure, entre 1854 y 1856, en el marco de viajes privados al Caribe y a México, se interesó en particular en los insectos. François Sumichrast, en la misma época y los mismos lugares, se desempeñó como ayudante del precedente y luego como comerciante naturalista (vendedor de especies). Y Alfred Moufflet, cirujano militar, anduvo por Martinica y México entre 1861 y 1863 (campaña

45. Su relato de viaje ha podido obedecer, por lo demás, a una intencionalidad política: incitar a Francia a cambiar el destino de México en beneficio de ambos países (abastecimiento para uno, modernización para otro), un cambio que ocurrió de manera temporal con el Imperio de Maximiliano (véase Águila: 93). 
militar francesa), interesándose en los insectos también (Moret: 407-408). O sea que apenas 4 de los 53 naturalistas de lengua francesa que viajaron a lugares de los antiguos imperios español y portugués de América durante el siglo XIX estuvieron en México. Por lo demás, los intereses de los franceses se orientaron mucho más hacia su imperio colonial de África y Asia y, en América, fueron mucho más activos los ingleses y los alemanes (Moret: 398) - también lo señala Mongne acerca de México, refiriéndose a la multiplicación de excavaciones a partir de finales del siglo XIX, debido a la relativa estabilización política durante el porfiriato (Mongne: 59). Los dos más famosos naturalistas del Museo de Historia Natural de París no anduvieron por México: Alcide d'Orbigny, al que ya nos hemos referido; y Auguste de Saint-Hilaire, entre 1816 y 1822, estuvo también en Brasil (véase también Kury 1995).

Es de saber que la mayor parte de los naturalistas eran más bien botanistas o naturalistas sin especialidad (Moret: 397). Por lo demás, pudieron los naturalistas tener profesiones muy diversas (o no tener), en cuanto viajeros o no viajeros de principios de la época contemporánea. Los entomólogos (para seguir con la subcategoría estudiada por Moret que sin duda se puede generalizar al conjunto de los naturalistas) eran médicos, oficiales de Marina, negociantes, eclesiásticos, funcionarios (diplomáticos, administración colonial en la Guayana francesa) y personas que vivían de sus rentas. Entre ellos, la mayor parte estaba constituida, fundamentalmente, de los que capturaban o recogían los ejemplares y datos para los científicos de gabinete que casi nunca viajaban -es decir que la dicotomía que ya había aparecido para el siglo XVIII, entre viajeros que organizaron grandes expediciones y grandes naturalistas que casi no viajaban, se perpetúa durante el siglo XIX. El único entomólogo de lengua francesa que haya estado en México y haya publicado trabajos científicos, o sea que fue a la vez recolector y estudioso mexicanista, fue Henri de Saussure (Moret: 397).

Importante también es la evolución que conoce esta práctica del viaje de exploración de la naturaleza: se van reduciendo mucho los viajes a lo largo del siglo y, además, a partir de mediados del siglo, desaparecen las expediciones oficiales (financiadas por el ministerio de Marina francés, el Museo de Historia Natural de París o por el museo de Historia Natural de Bruselas), sólo se mantienen expediciones financiadas por intereses privados (Moret: 399). El único caso de financiamiento público debido a un país de Mesoamérica y América del sur señalado por Moret es el de Chile cuyo gobierno empleó a naturalistas franceses durante varios años (401). Pero lo esencial del trabajo de recolección, lo hicieron intereses privados, sea aficionados a los insectos, sea negociantes (comerciantes) naturalistas. Moret señala una alusión de Henri de Saussure a Auguste Sallé, malhumorado al verlo llegar a México en 1855, ya que éste se había hecho negociante de insectos y de eso vivía dado que algunos ejemplares 
podían alcanzar precios muy altos en el mercado de los coleccionistas. Pero, para abastecer el mercado europeo, en general había que recurrir a cazadores autóctonos, o sea mano de obra local (405).

Moret concluye con dos ideas importantes: primero, es que la entomología francesa siguió siendo puramente descriptiva hasta el siglo XX, por esa diferenciación entre el recolector (o cazador) y el estudioso; es decir que no se abordaban problemáticas que no fueran clasificatorias (ni biológicas ni ecológicas); segundo, el cambio se dio cuando entomólogos de los propios países de Mesoamérica y América del sur empezaron a investigar sobre su propia fauna.

\section{Conclusión}

Fue en la perspectiva y el marco del décimo Congreso Mexicano de Etnobiología ( Rumbos y continuidades: Etnobiología y diversidad biocultural mexicanas », Mérida-Yucatán, 19-23 de septiembre de 2016, Centro Peninsular en Humanidades y Ciencias Sociales-Universidad Nacional Autónoma de México), en el que un biólogo, tres anglicistas y un hispanista de Burdeos fueron a mezclar su cultura con la de una multitud de etnobiólogos, invitados por su actual Presidente, Fabio Flores Granados, y su predecesor Juan Felipe Ruan Soto, que cobró consistencia esta intención de revisar el tema "Viajeros y naturalistas". El viaje, el intelectual, fue muy benéfico en varios sentidos: a no ser tomar conciencia de la extensión del tema y de las insorteables lagunas implicadas por un acercamiento general, nos dio sobre todo la oportunidad de confirmar la pertinencia del camino que íbamos siguiendo desde un principio, los miembros del comité editorial de la revista Elohi-Pueblos indígenas y medio ambiente, al tratar de tejer puentes, de cuerdas o de lo que fuera, entre nuestra formación y cultura literaria y/o de ciencias humanas, y la cultura llamada comúnmente "científica" (en sentido restringido). Cada vez que se trató de examinar un terreno, una temática, una problemática común, el encuentro puso de manifiesto, para nosotros una vez más, una cultura general e histórica también común, al lado de unas especificidades técnicas y metodológicas. Cómo no compartir orientaciones tales como el examen de "las múltiples interrelaciones entre los seres humanos y la naturaleza" o cuestiones sobre la dimensión social de este tipo de investigación, la de "el reconocimiento del otro" y "su papel en la construcción de la memoria biocultural de los pueblos originarios" ${ }^{\text {" }}$, por ejemplo.

Las lagunas que persisten aquí tienen que ver con la necesidad de elegir, a pesar de todo, a pesar (y a causa) de la amplitud de vistas que pretendió adoptar esta

46. Véase página de presentación del Congreso, http://xcetnobiologia.wixsite.com/xcmetnobiologia, última consulta, 15 de mayo de 2018. 
exposición ${ }^{47}$. Como el propósito no fue el de profundizar en un estudio de caso, y como se trató de hablar a la vez de viajeros y de naturalistas para llegar a ver aparecer convergencias, muchos no acudieron a la convocación. Tanto más que la perspectiva se extendió desde los momentos del contacto entre Europa y América hasta el siglo XIX. Ahora bien, la convergencia entre los unos, viajeros (animados por objetivos de conquista y de evangelización) y los otros, naturalistas (o por lo menos interesados en conocer la naturaleza), se dio desde un principio. No acudieron a la convocación casi todos los holandeses y portugueses, muchos ingleses y también, sin lugar a dudas, varios franceses, italianos y españoles ${ }^{48}$.

Pero esta presentación permitió, por lo menos, recordar dicha amplitud temática, fuera a través de sondeos entre las figuras más conocidas o destacadas, fuera a través del silencio mantenido en cuanto a muchas otras. Permite también percibir, a través de algunas muestras, la riqueza del corpus identificado y de la bibliografía secundaria adscritos al susodicho par de temas. Incluso se distinguen periodos, tendencias y algunas peripecias en la difusión y el comentario de las fuentes primarias, los relatos y también, los estudios propiamente naturalistas. Desde una perspectiva etnohistórica, permite, sobre todo, ver como también, en materia de conocimientos naturales, Europa destrozó, principalmente (v. g. Landa), pero también reconstituyó (v. g. Sahagún, Acosta) y, por lo demás, se aprovechó de una acumulación cultural de saberes tradicionales (v. g. Hernández, Monardes) ${ }^{49}$ que no quiso dejar aparecer como tales para poder inventarlos otra vez y según sus propias necesidades, objetivos y pautas.

Antes de finales del siglo XIX, con los primeros relatos biográficos de indígenas publicados en Estados Unidos ${ }^{50}$, el reconocimiento del otro y de su papel en la construcción de la memoria biocultural y social tuvo poca cabida (véanse los planteamientos contrastados de Tadeo Ortiz de Ayala, Lucas Alamán y José María Luis Mora para el caso mexicano, evocados por Delgado López: 118 y

47. Bastante parecida a lo que se puede encontrar, desde la perspectiva de Portugal y Brasil, en el artículo de Fernando Cristóvão, "A Literatura de Viagens e a História Natural".

48. Acerca de las colecciones de relatos de viajes del siglo XVI y de la inflación editorial en torno al género en Inglaterra en el siglo XVII y en Francia en el XVIII, véase Pimentel: 218 y ss.

49. Véase Navarro: 274.

50. Aparecen algunos casos a lo largo del siglo XIX. Véase Larré: 41-62. Es famosa la de Gerónimo, escrita con la colaboración de S.M. Barrett a eso de 1905. Véase (en francés) Mémoires de Géronimo (Geronimo, His Own Story, 1970), París: Maspero, 1972. En el mismo periodo, con el antropólogo Paul Radin, quien trabajó con el amerindio Sam Blowsnake, anticipando la renovación aportada por la Escuela de Chicago, iba a volverse un método de las ciencias sociales en Estados Unidos, y por influencia progresiva en otras regiones como América Latina y Europa (véase Pineau y Legrand; Stocking: y Levi-Strauss). 
ss). Los naturalistas intentaron aumentar los conocimientos del mundo natural, intentaron también medrar y vivir de su afición a tal o cual aspecto del mundo natural ${ }^{51}$, y la perspectiva de los indígenas sólo iba a ser tomada en cuenta muy progresivamente, a lo que parece, a pesar de lo que ya habían conseguido hacer esos pioneros que fueron Bernardino de Sahagún o José de Acosta ${ }^{52}$. A lo largo del siglo XIX, siguió interesando el saber en sí mismo, su dimensión universal, en coherencia con los ideales ilustrados y el liberalismo: acumular conocimientos, enriquecer la sociedad con conocimientos como se enriquecían ciertos pueblos y grupos sociales con innovaciones técnicas e industriales, y con la acumulación de haberes. No se trataba de tomar en cuenta "las múltiples interrelaciones entre los seres humanos y la naturaleza" (como rezaba la página web del Congreso de Etnobiología de Mérida antes citado). Interesaba la biodiversidad, eso sí, aunque no se usara esta terminología. Interesaban las diversas manifestaciones de la naturaleza pero poco la diversidad biocultural, es decir la relación particular de los diferentes grupos humanos con la naturaleza (el dualismo implícito es un comodín, en el presente discurso). La cuestión de las representaciones, es la que implica el interés por la diversidad biocultural. Y las representaciones de los pueblos no europeos sólo iban a interesar a lo largo del siglo XX, con la constitución de disciplinas como la antropología y la etnografía y seguirán algún tiempo todavía dependientes de intereses político-económicos, en el marco de los nuevos imperios coloniales o de relaciones poscoloniales en África y en Asia (Tibor Mende, De l'aide à la recolonisation). En países independientes de América, se ha podido tratar de integrar a la nación las poblaciones indígenas, es decir integrarlas en el proceso de modernización (como intentó pensarlo el mexicano Francisco Pimentel, en su Memoria sobre las causas que han originado la situación actual de la raza indígena de México y medios de remediarla, de 1864), lo que tampoco dejó un amplio espacio para tomar en cuenta la diversidad biocultural - en la historia del indigenismo mexicano, es un balance que parece haber sido hecho a partir de finales de los 1960 y principios de los 1970 (véase Vázquez León: 148-176). Sin embargo, parece bastante claro que la creación de instituciones y de programas por los propios países de

51. «Le voyage, tel qu'il se présente aux contemporains, est un phénomène d'appropriation intellectuelle et physique du monde qui mélange utopie, science, profit personnel, utilité publique et esprit de conquête " (Kury 2011 : 147).

52. Varias veces recuerda Cañizares Esguerra que, en la "epistemología clerical-criolla" o "epistemología patriótica” (Echeverría y Veytia, Eguiara y Eguren, Granados y Gálvez, Clavijero, etc.) que se elaboró en la segunda parte del siglo XVIII, como defensa de la cultura americana y crítica a los preconceptos y juicios de valor europeos de Buffon y demás, se ha valorado como confiables las fuentes amerindias cuando eran de las clases altas, y menospreciado todo lo que podía ser de origen plebeyo (Cañizares Esguerra: 369-446). 
América permitió dedicarse con más ahínco, y una visión menos exoticista, al estudio del patrimonio biocultural de los pueblos indígenas, lo que las estancias relativamente breves de los viajeros naturalistas de los siglos XVIII y XIX no permitían, a diferencia de lo que pudo ser el adentramiento en las culturas nativas por parte de misioneros en los tiempos del contacto y de la explotación incipiente del Nuevo Mundo (en el marco de la "conquista espiritual", véase Gomez: 271-289 $)^{53}$. Trabajos y publicaciones como las del Instituto Nacional Indigenista, en el caso de México, por ejemplo, demuestran una clara evolución, aunque se auspicie bajo la tutela de las grandes figuras del siglo XVI. Esto se puede comprobar al consultar la Flora medicinal indígena de México (tres tomos, 1994) ${ }^{54}$. Se insiste, incluso, en la dimensión "testimonial" del trabajo: una serie de encuestas en 28 pueblos, para recabar datos proporcionados por "234 sabedores, curanderos y amas de casa" (Argueta: 14). El autor de la introducción termina su presentación de la obra hablando de "deuda", de "deber" y de "antiguo deseo" cumplidos (ídem: 20).

53. El caso del jesuita Juan de Esteyneffer (1664-1716), y su labor en el noroeste de Nueva España (Nueva Vizcaya), ilustra la doble perspectiva seguida por ciertos misioneros: llevar a cabo un trabajo de control del territorio mediante no solamente la creación y gestión de misiones y demás formas de agrupación de indígenas (cuando se revelaba posible) sino también gracias a una sabiduría médica que permitía tejer interdependencia con las poblaciones y asegurar mejores condiciones para la evangelización; y al lado de esas formas de control territorial y evangélico, interesarse verdaderamente por las culturas autóctonas, asimilando y utilizando sus propias sabidurías para elaborar una cultura "científica" sincrética (hasta publicar y difundir muy ampliamente un manual de medicina, el Florilegio medicinal, 1713) en la que el reconocimiento de las culturas dominadas resultaba ser un hecho, pero implícito. Véase el estudio de Cabranes. La autora habla, en ese sentido, de "americanización de las prácticas y de los conocimientos de los misioneros" y a la vez de una "hispanización y estandarización del saber médico indígena” ( $\$ 67$ y 69 , traducción personal).

54. Son más de 1500 páginas dedicadas a catalogar los conocimientos tradicionales de las plantas medicinales en todo el territorio nacional. Cada página propone una representación gráfica de la planta o árbol y su nombre latín; y dos columnas para el nombre usual, la descripción, la localización, el uso medicinal y algunos otros datos: en la columna izquierda, en lengua indígena, en la derecha, en español. Los datos, mapas y dibujos fueron proporcionados por informantes de los diversos pueblos donde se hicieron las encuestas de este proyecto iniciado en 1989. Unos cuadros en la introducción general (tomo I) dejan aparecer una cantidad significativa de estudios sobre plantas medicinales y medicina tradicional entre los pueblos indígenas: v.g. 261 conciernen a los nahuas, 119 a los mayas; 66 a los purhepechas, 36 a los huicholes, 12 a los lacandones. Pero en la época, todavía no los había acerca de dichos conocimientos entre los quichés, los matlatzincas o los cakchiqueles (Argueta, 16-17). 
Tampoco hemos evocado hasta este momento, nombres de científicos latinoamericanos contemporáneos, en parte porque este recorrido no pretendía ir mucho más allá de la mitad del siglo XIX. Sin embargo, permítaseme un poco de drop name. En el tomo VI del Manual de Historia Universal dedicado a la historia de América, aparece una nómina de científicos del siglo XIX: "el astrónomo e ingeniero mejicano Joaquín Velázquez de León, el matemático peruano Miguel Garaicoechea, el naturalista uruguayo Dámaso Larrañaga, los mineralogistas peruanos Nicolás de Piérola y Mariano Eduardo Rivero, el naturalista argentino Francisco Javier Muñiz, el químico y médico mejicano Leopoldo Río de Loza, etc." (Morales Padrón: 369) Y la nómina se prolonga con nombres de paleontólogos, geógrafos, astrónomos, naturalistas y médicos; se concluye con el caso de Carlos Juan Finlay (1833-1915) quien demostró que la transmisión de la fiebre amarilla la causaba un mosquito (ídem:369-370).

Y del mismo modo que se ha ignorado hasta aquí este tipo de datos, también se ha ignorado el caso de los viajes en sentido inverso, de americanos a Europa (véase Ette: 32-33), como los de los proscritos argentinos en tiempos de Rosas que, al volver, llegaron con el Romanticismo en sus maletas, y como muchos más literatos, sabios y luego intelectuales, desde los albores de la Emancipación hasta hoy en día. Evidentemente, rastrear las huellas de científicos latinoamericanos en sus andanzas por Europa, de herederos de los naturalistas de los siglos XVIII y XIX, sería otra (presumida) tarea.

Para terminar con el balance autocrítico y siguiendo con la comprobación de la vastedad del tema, cabe decir que este panorama queda incompleto también porque deja de lado, como otra porción de la galaxia ni siquiera mencionada hasta ahora, la historia de las plantas, animales y remedios oriundos de América que estos viajeros y naturalistas contribuyeron en hacer conocer en Europa y en incorporar a la dieta y a la farmacopea de sus países (como, por ejemplo, la quina, anti palúdico, véase Minguet 1969: 573). Pero la enumeración (patata, tomate, cacao, maíz, guajolote, etc.) resultaría bastante estéril, sin la historia de sus usos y más, su prehistoria, la de su domesticación por los pueblos de América (véase Digard, artículo "Domestication”, cuya bibliografía cita, entre otras referencias, ensayos de Cuvier, Darwin y Saint Hilaire sobre el tema, y el estudio histórico de A. W. Crosby, Ecological Imperialism: The Biological Expansion of Europe, 900-1900, Cambridge: Cambridge University Press, 1986) ${ }^{55}$.

55. También se han dejado de lado los viajes y exploraciones identificados como falsos o basados en (semi)falsedades (siendo la búsqueda de El Dorado el caso más famoso). Véanse algunos ejemplos en Esteve Barba (305 y siguientes), los comentarios de Pimentel (capítulo 1 dedicado a cuestiones de veracidad y confianza; y los dos últimos sobre ficciones del viaje y la naturaleza como Robinson Crusoe y Pablo y Virginia) y los de Cristóvão 1999, "Introdução. Para una teoría da Literatura de Viagens" (50-52). 


\section{Bibliografía}

\section{Algunas fuentes citadas}

ACOSTA José de. [1590] Historia natural y moral de las Indias. Madrid: Ramón Anglés, 1894. En línea : https://archive.org/details/historianatural02acosrich, consultas de marzo de 2018.

ANGLERÍA Pedro Mártir de [1530]. Cartas sobre el Nuevo Mundo. Madrid: Polifemo, 1990.

BOUGAINVILLE Louis-Antoine. Voyage autour du monde par la frégate du Roi la Boudeuse, et la flûte L'Étoile en 1766, 1767, 1768 et 1769. Parsís: Saillant y Nyon, 1771. En línea : http://gallica.bnf.fr/ark:/12148/bpt6k852287d/f9.item. zoom, consultas de agosto de 2016.

BOUGAINVILLE Louis-Antoine. [1771] Voyage autour du monde par la frégate la Boudeuse et la flûte L'Étoile. París: Gallimard, col. Folio, 1982.

BOUGAINVILLE Louis-Antoine. [1772] Voyage autour du monde par la frégate la Boudeuse et la flûte L'Étoile. París: La Découverte, 2006.

BRASSEUR Charles [1860]. Viaje por el istmo de Tehuantepec (1859-1860). México: Fondo de Cultura Económica/Secretaría de Educación Pública, 1981.

BUFFON Georges-Louis Leclerc. Euvres complète de Buffon (édition de Frédéric Cuvier). París : Pillot, 1829. En línea : https://www.biodiversitylibrary. org/item/17783\#page/9/mode/1up, consultas de mayo de 2018.

BUFFON Georges-Louis Leclerc. [1758] CEuvres complètes. VII, Histoire naturelle, générale et particulière, avec la description du Cabinet du Roi. París: Honoré Champion, 2011, col. L'Âge des lumières.

CHARNAY Désiré [1863]. Le Mexique (1858-1861). Souvenirs et impressions de voyage. París: Éditions du Griot, 1987.

CHARNAY Désiré [1885]. Mis descubrimientos en México y la América Central. In América pintoresca. Descripción de viajes al nuevo continente. Barcelona: Montaner y Simon, 1884. 265-476.

CLAVIJERO Francisco Javier [1781]. Historia antigua de México. México; Porrúa, 1945 (reimpresión de 2014).

COLÓN Cristóbal. Textos y documentos completos (edición de Consuelo Varela y Juan Gil). Madrid: Alianza Universidad, 1995 (1 $1^{\text {era }}$ edición 1982).

COOK James. The Three voyages of Captain James Cook Round the World (in seven volumes). Londres: Longman, Hurst, Rees, Orme and Brown, 1821. En línea, https://www.biodiversitylibrary.org/bibliography/6760\#/summary, consultada el 30 de agosto de 2016 y el 30 de mayo de 2018).

CORTÉS Hernán. Cartas de relación. México: Porrúa, 2015 ( $1^{\text {era }}$ edición, 1960; edición a cargo de Manuel Alcalá). 
D’ORBIGNY Alcide [1834-1847]. Voyage dans l’Amérique méridionale. París : Pitois-Levrault, 1855. En línea : https://www.biodiversitylibrary.org/bibliography/85973\#/summary, consultas del 22 de julio de 2016 y mayo de 2018.

El libro de los libros de Chilam Balam. México: Fondo de Cultura Económica, 1948 (edición a cargo de Alfredo Barrera Vásquez y Silvia Rendón; col. Popular, 1972).

Escritores de Indias, I y II (edición de Manuel Ballesteros), Zaragoza: Ebro, 1961.

FERNÁNDEZ de OVIEDO Gonzalo [1526]. Sumario de la natural historia de las Indias. Madrid: Dastin, 2002.

Flora medicinal indígena de México. I, II, III. México: Instituto Nacional Indigenista, 1994.

GEMELLI CARERI Francisco. Voyage $d u$ tour $d u$ monde. Tome 6 e, De la Nouvelle Espagne. París: Étienne Ganeau, 1726. En línea: http://gallica.bnf.fr/ ark:/12148/bpt6k15116001/f12.image, páginas consultadas el 2 de febrero de 2018.

HUMBOLDT Alejandro de, BONPLAND Aimé. Essai sur la géographie des plantes. París: Levrault, Schoell y compañía, 1805. En línea: https://www.biodiversitylibrary.org/item/37872\#page/3/mode/1up, consultado el 13 de septiembre de 2016 y el 30 de mayo de 2018.

HUMBOLDT Alejandro de, BONPLAND Aimé. Viage a las regiones equinocciales del nuevo continente, hecho en 1799 hasta 1804, París: Rosa (Imprenta Pochard), 1826. En línea: https://www.biodiversitylibrary.org/item/76266\#page/1/mode/1up, consultas de marzo de 2018.

HUMBOLDT Alejandro de [1808]. Tableaux de la nature. París: Gide fils, 1828. En línea: http://www.biodiversitylibrary.org/title/40042\#page/7/mode/1up, consultas del 13 de septiembre de 2016 y del 30 de mayo de 2018.

HUMBOLDT Alejandro de [1810]. Vue des cordillères et des monumens des peuples indigènes de l'Amérique. París : Naze, 1824. En línea: https://www.biodiversitylibrary.org/item/156695\#page/9/mode/1up, consultas de marzo de 2018.

HUMBOLDT Alejandro de [1811]. Essai politique sur le royaume de la Nouvelle Espagne. París: Renouard, 1825. En línea: http://www.biodiversitylibrary. org/title/95434\#page/85/mode/lup, consultas del 13 de septiembre de 2016 y 30 de mayo de 2018.

HUMBOLDT Alexander von. Zentralamerika/Centroamérica. San José de Costa Rica: Editorial de la Universidad de Costa Rica, 2011.

JAN Michel. Le voyage en Asie centrale et au Tibet (anthologie des voyageurs occidentaux du Moyen Age à la première moitié du XXe siècle). París: Robert Laffont, col. Bouquins, 1992. 
LANDA Diego de [1560]. Relación de las cosas de Yucatán. México: Porrúa, 1959 (edición a cargo de Ángel María Garibay).

LINNÉ Carl von [1735]. Systema naturae. En línea, facsímile digitalizado descargable en formato PDF desde el Real Jardín Botánico de Madrid o pasando por el sitio de la Biodiversity Heritage Library (consultas de marzo de 2018)

LINNÉ Carl von [1744]. Systema naturae. $4^{\mathrm{a}}$ edición. En línea por el Real Jardín Botánico de Madrid y la Biodiversity Heritage Library (consultas de marzo de 2018).

LÖWENSTERN Isidore [1843]. México. Memorias de un viajero. México: UNAM, 2012.

MORELET Pierre-Arthur. Description des mollusques fluviatiles du Portugal. París: Baillière, 1845. En línea : https://books.google.fr/books?id=UScHAQAAIAAJ\&printsec $=$ frontcover\&hl=fr\&source $=$ gbs_ViewAPI\&redir_esc $=\mathrm{y} \#-$ $\mathrm{v}=$ onepage\&q\&f=false, consultas de septiembre de 2016 y mayo de 2018.

MOTOLINIA Fray Toribio. Historia de los indios de la Nueva España. México: Porrúa, 2014 (1969, edición a cargo de Edmundo O’Gorman).

NUÑEZ CABEZA DE VACA Âlvar. [1542] Naufragios. Madrid: Cátedra, col. "Letras Hispánicas". 1989.

RALEIGH Walter. His Apologie for his Voyage to Guiana. Londres: Moseley, 1650. Disponible en línea en la página de Early English Book Online, consulta del 30 de agosto de 2016.

SAHAGÚN Bernardino de. [1570] Historia general de las cosas de Nueva España. México. Imprenta Alejandro Valdés: 1829 (edición a cargo de Carlos María de Bustamante). En línea, https://archive.org/stream/historiagenerald01saha\#page/n11/mode/2up, páginas consultadas en febrero de 2018.

SESSÉ Martín de, MOCIÑO José Mariano. Flora Mexicana. México: Secretaría de Fomento, 1894. En línea, https://www.biodiversitylibrary.org/page/5875692\#page/1/mode/1up, consultas del 13 de septiembre 2016; y febrero-marzo de 2018).

STEPHENS John Lloyd. Incidents of Travel in Central America, Chiapas and Yucatán. New York: Harper, 1841.

STEPHENS John Lloyd. Incidents of Travel in Yucatán. New York: Harper, 1843.

STEPHENS John Lloyd. Aventures de voyages en pays maya. Copán, 1839. París : Pygmalion/UNESCO, 1991.

STEPHENS John Lloyd. Aventures de voyage en pays maya. Palenque, 1840. París : Pygmalion/UNESCO, 1993.

VV.AA. América pintoresca. Descripción de viajes al nuevo continente (Carlos Wiener, Doctor Crevaux, D. Charnay, etc., etc.). Barcelona: Montaner y Simón Editores, 1884. 


\section{Estudios consultados}

AGUILA Yves. Sans pitié le regard de Désiré Charnay sur le Mexique ? In Christian Lerat et al. (eds). Mythes et réalités transatlantiques. Dynamique des systèmes de représentation dans la littérature. Talence : Maison des Sciences de l'Homme d'Aquitaine, 1997. 85-96.

AGUILAR Jacques d'. Histoire de l'entomologie. París: Delachaux et Niestlé, 2006.

ALLORGE Lucile, IKOR Olivier. La fabuleuse odyssée des plantes. Les botanistes voyageurs, les Jardins des plantes, les Herbiers. París: Lattès, 2003.

AMORIM María Adelina. Frei Cristóvão de Lisboa, primeiro missionáro naturalista da Amazónia. In Fernando Cristovão (ed.). O olhar do viajante. Dos navegadores aos exploradores. 2003. 89-105.

ARGUETA Arturo. Introducción. In Flora medicinal indígena de México. I. México. Instituto Nacional Indigenista, 1994. 13-22.

BALLESTEROS GAIBROIS Manuel. Introducción. In Gonzalo Fernández de Oviedo. Sumario de la natural historia de las Indias. Madrid: Dastin, 2002. 5-48.

BAUDRY DE VAUX Jean. André Thévet et Jean de Léry, technique d'une polémique au XVIe siècle. In Yves Laissus (ed). Les naturalistes français en Amérique du Sud (XVIe-XIXe siècles). 1995. 13-24.

BÉNASSY Marie-Cécile, CLÉMENT Jean-Pierre (eds.). Nouveau Monde et renouveau de l'histoire naturelle II. París : Presses de la Sorbonne Nouvelle, 1993.

BÉNASSY Marie-Cécile, CLEMENT Jean-Pierre, PELAYO Francisco, PUIG SAMPER Miguel Ángel (eds). Nouveau monde et renouveau de l'histoire naturelle III. París: Presses de la Sorbonne Nouvelle, 1994. En línea : http://books.openedition.org/psn/989, consultado el 25 de mayo de 2018.

BÉNAT-TACHOT Louise. Substances comestibles, gastronomie et rituels alimentaires indigènes dans la Historia general y natural de las Indias de Gonzalo Fernández de Oviedo. In Marie-Cécile Bénassy, Jean-Pierre Clément, Francisco Pelayo, Miguel Ángel Puig Samper (eds). Nouveau monde et renouveau de l'histoire naturelle III. En línea : http://books.openedition.org/psn/997, consultado el 25 de mayo de 2018.

BERTRAND Michel, VIDAL Laurent (eds). A la redécouverte des Amérique. Les voyageurs européens au siècle des indépendances. Toulouse : Presses universitaires du Mirail, 2002.

BLAY Michel, HALLEUX Robert (eds). La science classique : XVI ${ }^{\mathrm{e}}$-XVIII $\mathrm{e}^{\mathrm{e}} \mathrm{iè-}$ cle. Dictionnaire critique. París: Flammarion 1998. 
BOULINIER Georges. Les leçons du tatou : d'Orbigny et Darwin en Amérique du Sud. In Yves Laissus (ed). Les naturalistes français en Amérique du Sud (XVIe-XIXe siècles). 1995. 277-290.

BRYGOO Édouard. La zoologie du voyage d'Alcide d'Orbigny. In Yves Laissus (ed). Les naturalistes français en Amérique du Sud (XVIe-XIXe siècles). 1995. 261-275.

CABRANES Amaia. Evangélisation, science et empire au tournant du siècle (fin du XVII ${ }^{e}$-début du XVIII ${ }^{e}$ siècle). Le Florilegio medicinal (1713) du frère jésuite Juan de Esteyneffer : un vade-mcum de médecine pour les missions de la Nouvelle Biscaye. Nuevo Mundo-Mundos Nuevos, 06/06/2017. En línea: http:// nuevomundo.revues.org/70839, consultado el 28 de mayo de 2018.

CALATAYUD ARINERO María de los Ángeles. Catálogo de las expediciones y viajes científicos españoles a América y Filipinas (siglos XVIII y XIX): fondos del Archivo del Museo nacional de ciencias naturales. Madrid: Consejo Superior de Investigaciones Científicas, 1984.

CANTARINO Vicente. Viajeros hispanos al Oriente en la Edad Media. In Salvador García Castañeda (ed). Literatura de viajes. El viejo y el nuevo mundo. 23-30.

CAÑIZARES ESGUERRA Jorge. Cómo escribir la historia del Nuevo Mundo. Historiografías, epistemologías e identidades en el mundo del Atlántico del siglo XVIII. México: Fondo de Cultura Económica, 2007 (primera edición en inglés, 2001).

CARRERA STAMPA Manuel. Relaciones geográficas de Nueva España, siglos XVI y XVIII. Estudios de historia novohispana, n², enero de 1968, 1-31.

CASTRILLÓN Alberto. Alexandre de Humboldt (1769-1859), un voyageur révolutionnaire. In Yves Laissus (ed). Les naturalistes français en Amérique du Sud (XVI'-XIX' siècles). 1995. 217-225.

CATALÁN PÉREZ-URQUIOLA Manuel. El viaje a la América ecuatorial para la medida del arco del meridiano. In Salvador García Castañeda (ed). Literatura de viajes. El viejo y el nuevo mundo. 105-114.

CHARDON Carlos E. Los naturalistas en la América Latina, tomo I. Trujillo: Editora del Caribe, 1949.

CHAUNU Pierre [1969]. Conquête et exploitation des nouveaux mondes. París : PUF, col. L'histoire et ses problèmes, 2011.

CHAVERO Alfredo. Boturini. Anales del Museo Nacional de México, 1, III, 1886. 236-245.

CHENU Jeanne. De la terre aux étoile : quête scientifique et identité culturelle en Nouvelle Grenade. In Groupe Interdisciplinaire de Recherche et de Documentation sur l'Amérique Latine. L'Amérique latine à lépoque des Lumières París: Editions du Centre National de la Recherche Scientifique, 1987. 247-260. 
CHENU Jeanne. Un apôtre de la science en Nouvelle Grenade à lépoque de Humboldt : José Celestino Mutis. In Jeanine Potelet, Joseph M. Farre (eds). Mundus Novus - Nouveaux mondes (XVIe-XXe s.). Hommage à Charles Minguet. Nanterre : ALLCA XX, col. Archivos, 1993. 103-121.

CLÉMENT Jean-Pierre. Des noms de plantes au XVIII siècle : Espagnols et Hispano-Américains à l'honneur. In Marie-Cécile Bénacy, Jean-Pierre Clément (eds.). Nouveau Monde et renouveau de l'histoire naturelle II. 1993. 85-109.

CLÉMENT Jean-Pierre. Réflexions sur la politique scientifique française visà-vis de l'Amérique espagnole au siècle des Lumières. In Marie-Cécile Benassy, Jean-Pierre Clement, Francisco Pelayo, Miguel Ángel Puig Samper (eds). Nouveau monde et renouveau de l'histoire naturelle III, 1994. En línea : http://books. openedition.org/psn/1003, consultado el 30 de mayo de 2018.

CLÉMENT Jean-Pierre. Le séjour du Père Claude D'Abbevile en l'île de Maragnan (1612). Létude de la nature. In Eduardo Mächler Tovar (ed). Voyageurs français dans les Amériques. París : Indigo et Côté-femmes, 2012. 19-54.

CONSTANTINO ORTIZ María Eugenia. José Longinos Martínez: un expedicionario, dos gabinetes de historia natural. Corpus [en línea], vol. 5, n²2, jul.-dic. 2015, consultado el 01 de julio de 2016. Disponible en http://corpusarchivos.revues.org/1467.

CRISTOVÃO Fernando (ed). Condicionantes culturais da literatura de viagens. Estudos y bibliografías. Lisboa: Edições Cosmos, 1999.

CRISTÓVÃO Fernando. Introdução. Para uma teoria da Literatura de Viagens. In Fernando Cristovão (ed). Condicionantes culturais da literatura de viagens. 1999. 183-218. 13-52.

CRISTOVÃO Fernando. A Literatura de Viagens e a História Natural. In Fernando Cristovão (ed). Condicionantes culturais da literatura de viagens. 1999. 183-218.

CRISTOVÃO Fernando (ed). O olhar do viajante. Dos navegadores aos exploradores. Coimbra: Almedina e Centro de Literaturas de Expressão Portuguesa da Universidade de Lisboa, 2003.

DELGADO LÓPEZ Enrique. El clima y la raza como parte de la historia de México en la primera mitad del siglo XIX. Revista de Historia de América, $\mathrm{n}^{\circ} 46$, enero-junio 2012. 113-133.

DEL PINO DÍAZ Fermín. L'Amérique et le développement de la science espagnole au XVIII ${ }^{e}$ siècle : tradition, innovation, représentations à propos de Francisco Hernández. In Groupe Interdisciplinaire de Recherche et de Documentation sur l'Amérique Latine. L'Amérique Espagnole à lépoque des Lumières. París: Centre National de la Recherche Scientifique, 1987. 101-121.

DEL PINO DÍAZ Fermín. Por la revalorización etnohistórica de una fuente olvidada: la crónica de Indias. In Thomas Calvo, Alain Musset (eds), Des Indes 
occidentales à l'Amérique latine 2. Mexico: Centre d'Études Mexicaines et Centraméricains/Institut des Hautes Études de l'Amérique Latine, 2006. 639-651. En línea : http://books.openedition.org/cemca/2137\#bodyftn10, consulta del 30 de mayo de 2018.

DEMAREST Arthur [2004]. Les Mayas. Grandeur et chute d'une civilisation. París: Tallandier, 2011.

DEPETRIS Carolina. El héroe involuntario. Frédéric de Waldeck y su viaje por Yucatán. México: UNAM, 2014.

DEPETRIS Carolina y Adrián CURIEL RIVERA. Geografías literarias de América. México: UNAM - Mérida: CEPHCIS, 2015.

DESCHAMPS Lucienne, MAROUSSY Annick. Botanistes voyageurs ou la passion des plantes. París: Aubanel, 2008.

DIAMOND Jared [2005]. Effondrement. París : Gallimard, col. Folio Essais, 2006.

DIGARD Jean-Pierre. « Domestication ». In Encyclopcedia Universalis: http:// www.universalis-edu.com/encyclopedie/domestication/, artículo consultado el 15 de mayo de 2018.

DUGAST Guy-Alain. L'hommage rendu à Alexandre de Humboldt dans quelques écrits publiés en France au XIX ${ }^{e}$ siècle. In Jeanine Potelet y Joseph Farré. Mundus Novus - Nouveaux Mondes (XVI ${ }^{\mathrm{e}}-\mathrm{X} \mathrm{X}^{\mathrm{e}}$ s.). 215-228.

DURAND-FOREST Jacqueline de, DURAND E. J. de. Aperçu de l'histoire naturelle de la Nouvelle Espagne d’après Hernández, les informateurs indigènes de Sahagún et les auteurs du Codex Badianus. In Nouveau Monde et renouveau de l'histoire naturelle I. París : Université de la Sorbonne Nouvelle-Paris III, 1986. 3-23.

DURAND-FOREST Jacqueline. Hernández y la botánica mexicana. Caravelle, $\mathrm{n}^{\circ} 55,1990.53-64$.

DURIS Pascal, GOHAU Gabriel. Histoire des sciences de la vie. París: Belin 2011.

DUVIOLS Jean-Paul. Voyageurs français en Amérique (colonies espagnoles et portugaises). París: Bordas, 1978.

DUVIOLS Jean-Paul. L'Amérique espagnole vue et rêvée. Les livres de voyages de Christophe Colomb à Bougainville. París: Promodis, 1985.

DUVIOLS Jean-Paul. Une nouvelle image de Humboldt. In Jeanine Potelet y Joseph Farré (eds). Mundus Novus. Nouveaux mondes (XVI ${ }^{\mathrm{e}}-X X^{\mathrm{e}}$ s.). 183-196.

DUVIOLS Jean-Paul. Les voyages clandestins du Sieur d'Accarette de Buenos Aires à Potosí (XVIIe siècle). In Ernesto Mächler Tovar (ed). Voyageurs français dans les Amériques. París : Indigo et Côté-femmes, 2012. 55-63.

D’OLWER Luis Nicolau. Fray Bernardino de Sahagún (1499-1590). México: Instituto Panamericano de Geografía e Historia, 1952. 
ESPAÑA PAREDES Romina. El espacio utópico en los relatos de viaje por Yucatán de Alice Dixon Le Plongeon. In Carolina Depetris (ed). Geografías literarias. México: UNAM, 2015. 181-210.

ESTEVE BARBA Francisco. Historiografía indiana. Madrid: Gredos, 1992.

ETTE Ottmar. Literatura de viaje (de Humboldt a Baudrillard). México: UNAM, 2001.

GALERA Andrés. Reflexiones sobre el modelo sistemático, el concepto de especie y el mecanismo de la reproducción, en el siglo XVIII. In Marie-Cécile Benassy, Jean-Pierre Clement, Francisco Pelayo, Miguel Ángel Puig Samper (eds). Nouveau monde et renouveau de l'histoire naturelle III, 1994. En línea : http://books.openedition.org/psn/1001, consultado el 30 de mayo de 2018.

GARCÍA CASTAÑEDA Salvador (ed). Literatura de viajes. El viejo y el nuevo mundo. Madrid: Castalia/The Ohio State University, 1999.

GERBI Antonello. La naturaleza de las Indias Nuevas (de Cristóbal Colón a Gonzalo Fernández de Oviedo). México: Fondo de Cultura Económica, 1992 (primera impresión, 1978).

GIL Juan. Mitos y utopías del Descubrimiento. 1. Colón y su tiempo. Madrid: Alianza, 1989.

GIL Juan. Viajes y viajeros. Modalidades y motivaciones desde la Antigüedad clásica hasta el Renacimiento. In Fernando Cristovão (coord.). O olhar do viajante. Dos navegadores aos exploradores. 2003. 289-309.

GOMEZ Thomas. L'invention de l'Amérique. Mythes et réalités de la Conquête. París : Flammarion, col. Champs, 1992.

GONZÁLEZ Roberto Martínez. La noción de persona en Mesoamérica: un diálogo de perspectivas. Anales de antropología, vol. 49.2 (2015). 13-72.

GONZÁLEZ ECHEVARRÍA Roberto. Mito y Archivo [1990]. México: Fondo de Cultura Económica, 1998.

GUILLAUME Jean. Ils ont domestiqué plantes et animaux : prélude à la civilisation, 2011. En línea http://sciences.scholarvox.com/bookdetails.aspx?docID $=450082388$, consulta del 7 de septiembre de 2016.

KURY Lorelai. La politique des voyages et la culture scientifique d'Auguste de Saint-Hilaire (1779-1853). In Yves Laissus (ed). Les naturalistes français en Amérique du Sud (XVIe-XIXe siècles). 1995. 235-245.

KURY Lorelai. Histoire naturelle et voyages scientifiques : (1780-1830). París : L'Harmattan 2001.

HALLEUX Robert. Histoire naturelle. In Michel Blay \& Robert Halleux. La science classique. XVI $I^{\mathrm{e}}$ XVIII ${ }^{\mathrm{e}}$ siècle. Dictionnaire critique. 712-731.

HALLEUX Robert. L'homme. In Michel Blay \& Robert Halleux. La science classique. XVIe-XVIIIe siècle. Dictionnaire critique. 734-748. 
LABORDE PEDELAHORE Philippe de, BOONE Chantal. Alcide d'Orbigny (1802-1857), dernier des naturalistes, premier des ethnologues. In Yves Laissus (ed). Les naturalistes français en Amérique du Sud (XVI e-XIX siècles). 1995. 249259.

LAISSUS Yves (ed). Les naturalistes français en Amérique du Sud (XVIe-XIXe siècles). París: Editions du Comité des travaux historiques et scientifiques, 1995.

LARRE Lionel. Autobiographie amérindienne. Pouvoir et résistance de l'écriture de soi, Pessac: Presses Universitaires de Bordeaux, 2009.

LAVALLÉ Bernard. L'Amérique espagnole de Colomb à Bolivar. Paris: Belin Sup, 1993.

LEGRAND Goulven. Alcide d'Orbigny (1802-1857) : géologie et paléontologie de son voyage en Amérique du Sud, 1826-1834. In Yves Laissus (ed). Les naturalistes français en Amérique du Sud (XVIe-XIXe siècles). 1995. 291-305.

LEÓN-PORTILLA Miguel. Visión de los vencidos: relaciones indígenas de la Conquista. México: Universidad Nacional Autónoma de México, 1959.

LEÓN-PORTILLA Miguel. Bernardino de Sahagún. Madrid: Quorum, 1987.

LÉVI-STRAUSS Claude. Simmons (Leo W.) - Ed. Sun Chief, The Autobiography of a Hopi Indian. L'Année sociologique, Tercera serie, 1940-1948, Tomo Primero, 1949. 329-330.

LLORCA Jaume Josa. La Historia Natural en la España del siglo XIX: Botánica y Zoología. Ayer, nº " "La ciencia en la España del siglo XIX", 1992. 109-152.

MÄCHLER Ernesto (ed). Voyageurs français dans les Amériques. París: Indigo et Côté femmes, 2012.

MALDONADO-KOERDELL Manuel. Naturalistas extranjeros en México. Historia Mexicana, Vol. 2, No. 1 (Jul. - Sep., 1952). 98-109.

MALDONADO POLO J. Luis. La principal contribución de José Longinos Martínez en el reino de Guatemala: el Gabinete de Historia Natural. In Marie-Cécile Bénassy, Jean-Pierre Clément, Francisco Pelayo, Miguel Ángel Puig Samper (eds). Nouveau monde et renouveau de l'histoire naturelle III. En línea : http://books.openedition.org/psn/1012, consultado el 30 de mayo de 2018.

MALDONADO POLO J. Luis. La expedición botánica a Nueva España, 1786-1803: el Jardín Botánico y la cátedra de botánica. Historia Mexicana, Vol. 50, Nº 1 (Jul.-Sep., 2000). 5-56.

MANIGAT Leslie [1973]. L’Amérique latine au XXe siècle (1889-1929). París : Seuil, 1991, col. Points.

MARTÍNEZ Carolina. Usos del pasado y confiabilidad de las fuentes: Antoine-Joseph Pernety y la disputa sobre la naturaleza de América en el siglo XVIII. Corpus [en línea], vol. 5, $\mathrm{n}^{\circ}$ 2, jul.-dic. 2015, consultado el 24 de junio 2016. Disponible en http://corpusarchivos.revues.org/1449. 
MAURO Frédéric. "Découvertes (grandes) ». In Universalis éducation [en ligne]. Encyclopcedia Universalis, página consultada el 22 de julio de 2016. Disponible en http://www.universalis-edu.com/encyclopedie/grandes-decouvertes/.

MENDE Tibor. De l'aide à la recolonisation. París : Seuil, 1972.

MINGUET Charles. Alexandre de Humboldt. Historien et géographie de l'Amérique espagnole (1799-1804). París: Maspero, 1969.

MINGUET Charles. Alejandro de Humboldt ante la ilustración y la independencia de Hispanoamérica. In Homenaje a Noël Salomon. Ilustración española e independencia de América. Barcelona: Universidad Autónoma de Barcelona, 1979. 69-79.

MINGUET Charles. «Humboldt Alexander von - (1769-1859) ». En Encyclopodia Universalis: http://www.universalis-edu.com/encyclopedie/alexander-von-humboldt/ consulta del 22 de julio de 2016.

MONGNE Pascal. L'Américanisme. Genèse et évolution d'une science. In Désiré Charnay. Le Mexique (1858-1861). Souvenirs et impressions de voyage. 1114.

MONGNE Pascal. Désiré Charnay : explorateur, archéologue, photographe et écrivain. In Désiré Charnay. Le Mexique (1858-1861). Souvenirs et impressions de voyage. 21-80.

MORALES PADRÓN F. Manual de Historia Universal. Tomo VI. Historia general de América. Madrid: Espasa-Calpe, 1962.

MORANGE Michel. Une histoire de la biologie. París: Seuil, col. Points, 2016.

MORET Pierre. Entomologistes et chasseurs d'insectes en Amérique du Sud au XIX ${ }^{e}$ siècle. In Yves Laissus (ed). Les naturalistes français en Amérique du Sud, XVI $I^{\mathrm{e}}$-XIX ${ }^{\mathrm{e}}$ siècles. 395-408.

NAVARRO Víctor. Edad Moderna. In Javier Ordóñez, Víctor Navarro, José Manuel Sánchez Ron. Historia de la ciencia. Madrid: Espasa-Calpe, col. Austral, 2004. 233-424.

NICOLAÏDIS Efthymios. Voyages et voyageurs. In Michel Blay \& Robert Halleux (eds). La science classique. XVIe-XVIIIe siècle. Dictionnaire critique. 165176.

ORTEGA y MEDINA Juan A. Humboldt desde México. México: UNAM, 1960.

PARDO TOMÁS José. Oviedo, Monardes, Hernández. El tesoro natural de América. Colonialismo y ciencia en el siglo XVI. Madrid: Nivola, 2002.

PARDO TOMÁS José, LÓPEZ TERRADA María Luz. Las primeras noticias sobre plantas americanas en las relaciones de viajes y crónicas de Indias (14931553). Valencia: Instituto de Estudios Documentales e Históricos sobre la Ciencia, 1993. 
PASO Y TRONCOSO Francisco del. Estudio sobre la historia de la medicina en México. Primer estudio. La botánica entre los nahuas (I a IV). Anales del Museo Nacional de México, 1, III, 1886, 137-235.

PELAYO Francisco, PUIG SAMPER Miguel Ángel. Las actividades científicas de Joseph de Jussieu en América del Sur. In Marie-Cécile Bénacy, Jean-Pierre Clément (eds.). Nouveau Monde et renouveau de l'histoire naturelle II. 1993. 67-85.

PELT Jean-Marie. La cannelle et le Panda : les grands explorateurs naturalistes autour du monde. París: Fayard, 1999.

PHILIPPON Jacques. « Orbigny alcide Dessalines d'- (1802-1857)». In Universalis éducation [en ligne]. Encyclopcedia Universalis, consulta del 22 de julio e 2016. En línea, http://www.universalis-edu.com/encyclopedie/orbigny-alcide-dessalines-d/.

PIMENTEL Juan. Testigos del mundo: ciencia, literatura y viajes en la Ilustración. Madrid: Marcial Pons, 2003.

PINAULT SORENSEN Madeleine. Le livre de botanique, XVII et XVIII siècles. París: Bibliothèque Nationale de France, 2008.

PINEAU Gaston, LE GRAND Jean-Louis. Les Histoires de vie. París: PUF, col. «Que sais-je ? », 2007.

POTELET Jeanine, FARRE Joseph (eds). Mundus Novus - Nouveaux Mondes $\left(X V I^{\mathrm{e}}-X X^{\mathrm{e}}\right.$ s.). Hommage à Charles Minguet. Nanterre: ALLCA XX, col. Archivos, 1993.

PUIG SAMPER Miguel Ángel. Illustrators of the New World. The Image in the Spanish Scientific Expeditions of the Enlightenment. Culture and History Digital Journal, vol. 1, n², 2012. En línea : http://cultureandhistory.revistas. csic.es/index.php/cultureandhistory/article/viewArticle/12/43, consulta del 19 mars 2018.

ROGER Jacques. Buffon, Jefferson et l'homme américain. Bulletins et Mémoires de la Société d'anthropologie de Paris. Nueva Serie, vol. 1, n³-4, 1989. 57-65.

RUZ Mario Humberto, PENICHE GARCÍA Eréndira (eds). Del mar y la tierra firme. Miradas viajeras sobre los horizontes peninsulares. México: UNAM/ CEPHCIS, 2011.

SÁNCHEZ Jesús. Reseña histórica del Museo Nacional de México. Anales del Museo Nacional de México, vol. I, $\mathrm{n}^{\circ} 1,1877$. 1-2.

SÁNCHEZ ALMAZÁN Javier. Historia del Museo. Fundación y primera época (1771-1814). En línea: http://www.mncn.csic.es/Menu/Elmuseo/Historia/seccion=1599\&idioma=es_ES.do, consulta del 30 de mayo de 2018.

SERNA Mercedes. Discursos sobre la naturaleza americana: desde el descubrimiento de América hasta la visión ilustrada. Anales de Literatura Hispanoamericana, vol. 39, 2010. 251-264. 
SERRA Daniela. Reseña sobre Miruna Achim e Irina Podgorny (eds.), $\mathrm{Mu}$ seos al detalle. Colecciones, antigüedades e historia natural (1790-1870). Historia, vol. I, ${ }^{\circ} 48$, enero-junio de 2015. 333-336.

SIGWALT-DUMOTIER Eliane. Les voyageurs naturalistes au XVI ${ }^{e}$ siècle : André Thévet (1504?-1592). In Yves Laissus (ed). Les naturalistes français en Amérique du Sud (XVI ${ }^{\mathrm{e}}$-XIX $\mathrm{X}^{\mathrm{e}}$ siècles). 1995. 25-41.

SOMOLINOS D’ARDOIS Francisco. Tras la huella de Francisco Hernández: la ciencia novohispana del siglo XVIII. Historia Mexicana, vol. 4, n²2, 1954. 174-197.

SPITZ Sophie. "Histoire naturelle ». In Universalis éducation [en ligne]. Encyclopredia Universalis, consulta del 22 de julio de 2016. En línea, http://www. universalis-edu.com/encyclopedie/histoire-naturelle/.

STEVENS-MIDDLETON Rayfred Lionel. La obra de Alexander von Humboldt en México : fundamento de la geografía moderna. México: Instituto Panamericano de Geografía e Historia, 1956.

STOCKING George W. Anthropology at Chicago. Chicago: The University of Chicago Library, 1979.

TALADOIRE Éric. Reseña sobre Stephens, J. L., Aventures de voyage en pays maya I (Copan, 1839). Journal de la Société des Américanistes, vol. 78, nº 1, 1992. 172-173.

TRYSTRAM Florence. Aimé Bonpland (1773-1858) en Argentine. In Yves Laissus. Les naturalistes français en Amérique du sud, XVI ${ }^{\mathrm{e}}-X I X^{\mathrm{e}}$ siècles. 227-234.

TULARD Jean (ed). L'Amérique espagnole en 1800 vue par un savant allemand, Humboldt. París: Calmann-Lévy, 1965.

URQUIJO TORRES Pedro S. Humboldt y el Jorullo. Historia de una exploración. México: UNAM, 2008.

VALENCIA Fernanda. Visiones inglesas sobre la región maya en el siglo XVI. Península, Vol. X, n 2, 2015. 71-96.

VÁZQUEZ LEÓN Luis. La historiografía antropológica contemporánea en México. In Carlos García Mora (ed.). La antropología en México: panorama histórico (Tomo 1). México: Instituto Nacional de Antropología e Historia, 1987. 139-212.

VAYSSIERE Pierre. Postface. D'Orbigny et la redécouverte des Amériques. In Michel Bertrand y Laurent Vidal (eds.). A la redécouverte des Amériques. Les voyageurs européens au siècle des Indépendances. 252-258.

VEGA y ORTEGA Rodrigo. Recreación e instrucción botánicas en las revistas de la ciudad de México, 1835-1855. Historia Crítica, n49, 2013. 109-133.

VENTURA Antoine, LARRÉ Lionel, MACHET Laurence. Ressources du vivant/Recursos del mundo vivo. Elohi-Peuples indigènes et environnement, $\mathrm{n}^{\circ} 5 / 6$, 2014. 3-25 (http://journals.openedition.org/elohi/688). 
VICTORIA OJEDA Jorge. El pirata catalán Miguel Molas y su descripción de la costa peninsular, 1817. In Mario Humberto Ruz, Eréndira Peniche García (eds.). Del mar y la tierra firme. Miradas viajeras sobre los horizontes peninsulares.73-88.

VILLEGAS Pascale. Fotógrafo, viajero, escritor, arqueólogo y espía francés en tierras mayas: Désiré Charnay. In Mario Humberto Ruz, Eréndira Peniche García (eds.). Del mar y la tierra firme. Miradas viajeras sobre los horizontes peninsulares. 155-166.

WACHTEL Nathan. La vision des vaincus (les Indiens du Pérou devant la Conquête espagnole, 1530-1570). París: Gallimard, 1971, coll. Folio, 1992.

ZOLLA Carlos, ARGUETA Arturo. Presentación. In Flora medicinal indígena de México. I. México: Instituto Nacional Indigenista, 1994. 11-12.

Résumé : Une double thématique aussi ample que celle des voyageurs et des naturalistes implique de survoler quatre siècles de relations entre l'Europe et l'Amérique, qui sont des siècles de conquête, d'exploration et d'exploitation, ayant donné lieu d'emblée à des observations sur la nature, y compris de la part des premiers navigateurs et autres marins, et de manière plus approfondie, à des chroniques voire à des études, parfois très attentives aux savoirs autochtones, en particulier de la part de certains missionnaires. La fin de l'époque moderne et le début de l'époque contemporaine sont le moment d'une « seconde découverte » caractérisée par la soif de connaissances, de contrôle de la nature propre à la culture des Lumières, et de demande économique d'une Europe en phase d'industrialisation. Cette redécouverte s'est traduite par de nombreux voyages et expéditions officielles ou privées et par une quantité considérable de publications (notamment de récits de voyage). Cette période s'avère, néanmoins, assez pauvre d'un point de vue ethno-historique, la part des connaissances et des discours et visions du monde naturel attribuables aux populations locales faisant défaut, pour l'essentiel, en dehors de la redécouverte des vestiges archéologiques et de manuscrits égarés au cours des siècles antérieurs. Il faut attendre l'institutionnalisation de sciences comme l'anthropologie, pour que prenne forme progressivement un regard américain moins surplombant et moins marqué par la démarche d'appropriation (théorique et pratique) de la diversité culturelle et bio-culturelle. Le panorama esquissé ici met en évidence, cela étant, l'intérêt assez constant et l'attraction forte exercée sur les Européens par le continent américain, en tant que réservoir d'altérité et de biodiversité.

Mots-clés : voyageurs, naturalistes, Nouveau Monde, Mexique, sciences, ethnohistoire

Resumen : Una doble temática tan amplia como la de "viajeros y naturalistas" implica un recorrido muy general por cuatro siglos de relaciones entre Europa y América, cuatro siglos que fueron de conquista, de exploración y de explotación. Inmediatamente, estos procesos dieron lugar a observaciones sobre la naturaleza, incluso por parte de los primeros navegadores y marineros $y$, de forma más profundizada, a crónicas y estudios a veces muy atentos a los saberes autóctonos, en particular por parte de algunos misioneros. A finales de la edad moderna y principios de la edad contemporánea se dio un "segundo descubrimiento" caracterizado por la sed de conocimientos, de dominio sobre la naturaleza típicos de la cultura ilustrada, y de demanda económica por parte de una Europa que iba industrializándose. Este redescubrimiento se reflejó en los numerosos viajes y expediciones oficiales o privadas, y en una cantidad notable de publicaciones (en particular de relatos de viaje). Este periodo resulta ser, sin embargo, bastante pobre desde un punto de vista etnohistórico ya que, fuera del redescubrimiento de ruinas arqueológicas y manuscritos perdidos durante siglos, pocos conocimientos, discursos y visiones del mundo natural eran referidos a las poblaciones locales. Hubo que esperar la institucionalización de ciencias como la antropología para que se concretara una 
mirada americana menos vertical y menos determinada por la apropiación (teórica y práctica) de la diversidad cultural y biocultural. El panorama esbozado pone de realce, a pesar de todo, el interés relativamente constante y el atractivo fuerte ejercido en los europeos por el continente americano, como fuente de alteridad y de biodiversidad.

Palabras claves : viajeros, naturalistas, Nuevo Mundo, México, ciencias, etnohistoria

Antoine Ventura : profesor titular en la Universidad Bordeaux Montaigne y miembro del equipo de investigadores AMERIBER (EA 3656). Cofundador de Elohi-Pueblos indígenas y medio amiente, asume la dirección de la revista desde el año 2015. Ha sido el coordinador de los números 5/6, “Recursos del mundo vido" y 7, "Ecoturismo". Sus temas de investigación conciernen el testimonio latinoamericano, las relaciones entre literatura y antropología, así como la historia de la antropología en México.

Antoine Ventura : maître de conférences à l'Université Bordeaux Montaigne et membre de l'équipe d'accueil AMERIBER (EA 3646). Co-fondateur de la revue Elohi-Peuples indigènes et environnement, il en assume la direction depuis 2015. Il a spécifiquement coordonné les numéros 5/6, « Ressources du vivant » et 7 «Écotourisme ». Ses axes de recherche concernent la littérature de témoignage d'Amérique latine, les rapports entre littérature et anthropologie, ainsi que l'histoire de l'anthropologie au Mexique. 
